\title{
Modeling Turbulent Dispersion on the North Flank of Georges Bank using Lagrangian Particle Methods
}

\author{
Jeffrey A. Proehl, Daniel R. Lynch, ${ }^{1}$ Dennis J. McGillicuddy, Jr., ${ }^{1}$ James R. Ledwell \\ Dartmouth College, Hanover, NH, USA \\ ${ }^{1}$ Woods Hole Oceanographic Institution, Woods Hole, MA USA \\ To Appear, Continental Shelf Research \\ Sept. 22, 2004
}

\begin{abstract}
Circulation and transport at the North Flank of Georges Bank are studied using a dataassimilative 3-D model of frontal dynamics under stratified, tidally-energetic conditions over steep topography. The circulation model was used in real-time during a cross-frontal transport study. Skill is evaluated retrospectively, relative to CTD, ADCP, drifter, and flourescent dye observations. Hydrographic skill is shown to be retained for periods of weeks, requiring only initialization from routine surveys and proper atmospheric heating subsequently. Transport skill was limited by the wind stress input; real-time forecast winds taken from an operational meteorological model produced cross-isobath Ekman transport which was not observed locally. Retrospective use of observed local wind stress removed this cross-frontal bias.

The contribution of tidal-time motion to the dispersion of a passive tracer is assessed using an ensemble of passive particles. The particle release simulates an at-sea dye injection in the pycnocline, which is followed for 4 days. Non-advective vertical tracer transport is represented as a random walk process sensitive to the local eddy diffusivity and its gradient, as computed from the turbulence closure. Non-advective horizontal tracer transport is zero for these ensembles. Computations of ensemble variance growth support estimates of (Lagrangian) horizontal dispersion.

Off-bank, ensembles are essentially non-diffusive. As an ensemble engages the mixing front, its vertical diffusivity rises by 3 orders of magnitude, and horizontal spreading occurs in the complex front. The resultant horizontal dispersion is estimated from the ensemble variance growth, in along-bank and cross-bank directions. It is partitioned, roughly, between that contributed by 3 -D advection alone, and that initiated by vertical diffusion.

Engagement in the mixing front occurred in the forecast ensemble as a result of Ekman drift produced by an erroneous wind prediction. In the hindcast, observed wind left the ensemble nondiffusive and compact, advecting parallel to the mixing front and experiencing some advective shear dispersion.

Lagrangian dispersion is event-specific and both simulations here represent credible events with dramatically different ecological outcomes. The skill metrics used are less sensitive, indicating that metrics tailored to surface-layer phenomena would be more appropriate in a dataassimilative context. The hindcast is closer to truth, based on first principles (better information). The level 2.5 closure used is realistic in the ocean interior; the near-surface processes need further refinement, especially as both surface- and bottom-generated turbulence affect these events strongly.
\end{abstract}




\section{Introduction}

Georges Bank has been a focus of oceanographic activity for over 50 years. It is a shallow bank, depth $<60 \mathrm{~m}$, length scale $\sim 150 \mathrm{~km}$, on the eastern North American shelf (Figure 1). It separates the deeper shelf basins of the Gulf of Maine from the Atlantic Basin, and straddles the territorial waters of the US and Canada. It has been home to an important commercial fishery since European contact; this and other offshore economic activities have attracted mariners and oceanographers to it, such that there is a large accumulated literature. In the 1970's the community produced the landmark multidisciplinary volume by Backus and Bourne [2]. The decadal MARMAP program (MArine Resources Monitoring Assessment and Prediction) reflected sustained US Agency interest in the physical and biological features of the Bank, in a larger US East Coast context [38, 35, 4, 27]. In turn the US GLOBEC program (Global Ocean Ecosystem Dynamics) initiated its Northwest Atlantic study over the Bank during the 1990's, leading to three refereed volumes $[45,46,3]$ and an ongoing synthesis effort.

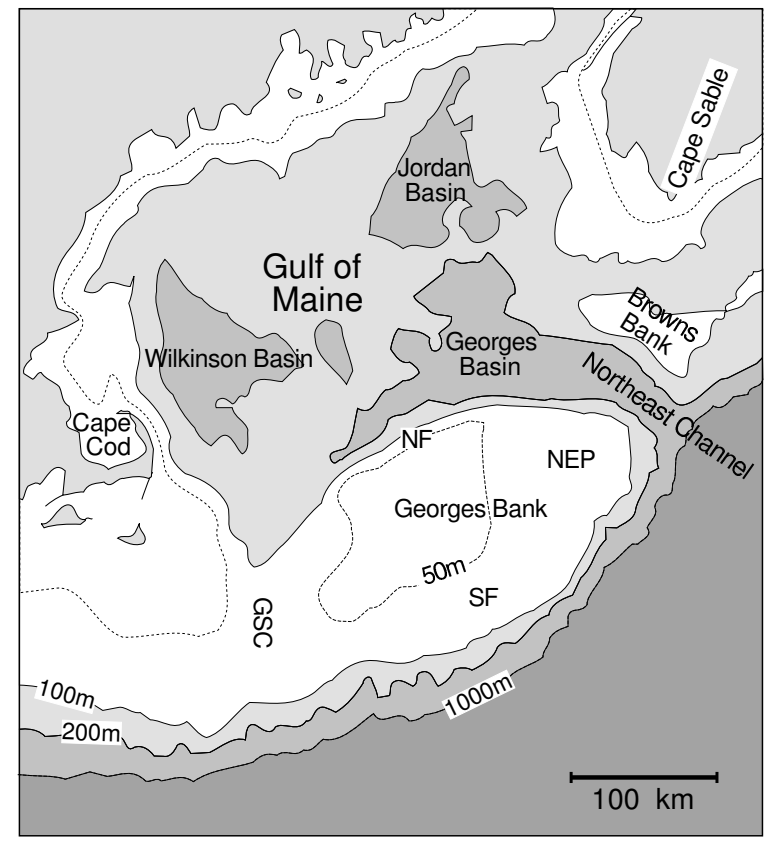

Figure 1: Georges Bank. The four sectors of the bank indicated are NF (North Flank), NEP (NorthEast Peak), SF (South Flank) and GSC (Great South Channel, sill depth $70 \mathrm{~m}$ ). The three basins of the gulf of Maine connect to the Atlantic basin through Northeast Channel (sill depth 230 $\mathrm{m})$. The US/Canada boundary crosses NEP. From [24].

Fundamental to Georges Bank phenomena is the predictable occurrence of a mixing front surrounding the shallow bank top. The attendant frontal circulation patterns reflect variability at many scales, against a backdrop of tidally-generated bottom turbulence. The work to date confirms that important biological aspects of the Bank depend critically on physical/biological interactions in this frontal system. $[15,41,44,18,22,30,26,17,1]$.

In previous work we have concentrated on the development of a real-time forecasting system which can be deployed at sea, in direct contact with the in situ data and the scientists conducting 
the sampling. Our basic system is rooted in a standard 3-D physical simulator. Using this we construct limited-area oceanic forecasts, concentrating simulation detail over the Bank itself but bounding the simulation close in. This simulator is fed by local observation of wind, current and hydrography, and by estimated remote influences (the unmeasured meteorological forcing; the farfield oceanic influences incident on the forecast domain; and the cross-boundary fluxes) which are represented through formal and necessary boundary conditions. In a series of papers we have reported progress on the simulator itself [20], its resolution [16], and its fidelity [11, 31]. More recently we have developed an assembly of data-assimilation modules for estimating improperlyposed fields as encountered in this context [24, 21, 19, 23]. Use of an assembly of some of these modules at sea in 1999 is reported in [22].

The present paper reports a retrospective analysis of that data-assimilative simulation system, with two basic goals. First, we examine retrospectively the forecast skill; the primary parameters contributing to skill; and the comparison between hindcast and forecast. And secondly, we examine the modeled dispersion of a passive tracer released near the front, with the goal of assessing the mechanisms of cross-frontal transport. Fundamentally, our hypothesis is that tidal-time Reynolds' stresses in the vertical cause passive tracers to diffuse vertically within a dynamic and highly structured 3-D velocity field; 3-D advection in tidal time moves parcels within a highly variable vertical diffusivity field; and the resulting shear dispersion accounts for the bulk of the horizontal non-advective transport. To simulate this, we resolve 3-D advective motions in tidal time and close the vertical transport in a conventional, highly dynamic level 2.5 eddy viscosity closure. Tracer transport is computed with an ensemble of 10,000 Lagrangian particles with deterministic 3-D advection and stochastic vertical diffusion. There is no separate non-advective horizontal transport mechanism; but horizontal dispersion results, manifest as ensemble variance growth.

The events modeled here are based on data and forecasts initially achieved and archived aboard $\mathrm{R} / \mathrm{V}$ ENDEAVOR, Cruise 324. This cruise was tasked with injection and tracking of fluorescent dye at the pycnocline along the northern flank of the bank, on the stratified side of the mixing front. The 1999 operations are sketched in Figure 3. While our data-assimilative approach keeps us close to the observed circulation and hydrography, the results relative to dispersion are not explicitly constrained by observation. They are representative of real conditions but still limited by weaknesses of inference about unobserved processes. This reliance on modeled outcomes is almost guaranteed by the detailed nature of the phenomena under study, the undersampling that results from practical constraints on the real-time operation, and the associated ill-posedness of the mathematics.

It is clear that the Northern Flank front of this Bank presents serious modeling challenges. The topographic slope is of order $10^{-2}$, over a depth range roughly $50-150 \mathrm{~m}$. Tidal velocity is large (order $1 \mathrm{~m} / \mathrm{s}$ ) and rotary. Its rectification in the presence of stratification creates subtidal velocity of order $0.3 \mathrm{~m} / \mathrm{s}$ along-bank, a mixing front which relocates in tidal time following the tidal excursion; along-bank transport of order $0.1 \mathrm{~Sv}$; and well-mixed conditions on the bank crest. It is also clear that our modeled environment is a realistic facsimile. The earliest 3-D studies have produced remarkably rich and realistic space-time structures in density, velocity, and turbulent mixing, given adequate resolution and proper vertical closure. (See [20, 37, 44]). Climatological forcing produces a frontal structure in general agreement with comparable observation [11, 32, 31]. Here we fit these fields to observed conditions as in [22], and explore the Lagrangian mixing regime implied. For a comparable study of the southern flank of the bank, see [1] 


\section{Model Setup}

Our simulations are discretizations of the 3-D shallow water equations. The horizontal mesh for the present study is shown in figure 2. The vertical is represented on a generalized surface- and terrain-following coordinate system, with level 2.5 closure [29] and important later refinements as reported by Galperin et al. and Blumberg et al. $[9,5]$.

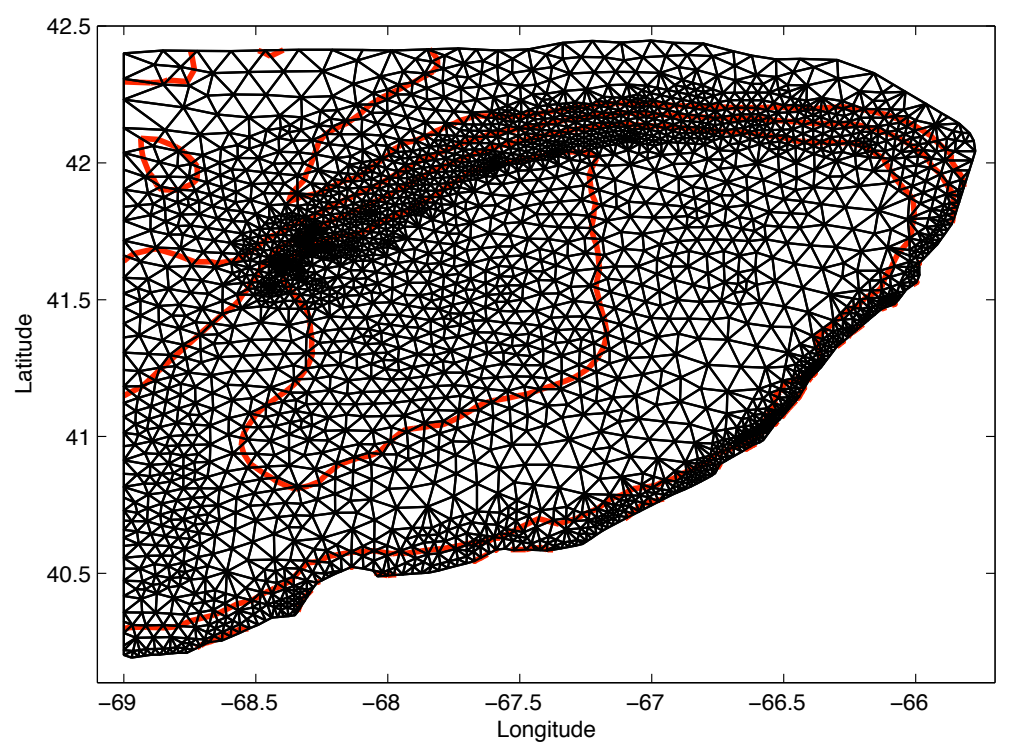

Figure 2: Triangular mesh, "gbk1". Isobaths are plotted here and throughout at 50,100,150, and $200 \mathrm{~m}$.

Initial conditions on this mesh were objectively analyzed from the most recent hydrographic survey of the Bank (OCEANUS 341, April 17-26 1999) (figure 3). Motion and turbulence were started from rest. Figure 3 also shows the general area of ENDEAVOR operations, and the Simpson-Hunter [39] mixing line indicating the expected mixing front location, as estimated from earlier tidal studies based on $\bar{U}^{3} / H$.

Wind stress and heat flux were computed from shipboard observations using standard bulk formulae. For the forecast, these fluxes were forecast from standard NCEP products for the region. In either case, atmospheric fluxes were assumed spatially uniform over the mesh.

The general operational timeline for model inputs is illustrated in Figure 4. Each forecast spans 13 modeled days. There is a 3-day spinup followed by 5 more simulated days before local observations begin. There are two "bell times", atmospheric and oceanic. Data available before the relevant bell are available for assimilation in the relevant simulation. The atmospheric hindcast and forecast products were taken from standard NCEP operational products. For the oceanic simulation, atmospheric data from the ship were used up until the oceanic bell; thereafter the NCEP atmospheric forecast product was used. (In the gap between bells, some discrepancies between local and forecast wind were common. We favored the local observation.) ADCP data were assimilated into the oceanic simulation up until the oceanic bell (we actively "fitted" that data). The post-bell ADCP and all the CTD and drifter observations were "passive" i.e. not assimilated. The general approach is as described in [22]. Post-bell, the oceanic boundary conditions deduced from the hindcast were maintained without change. 


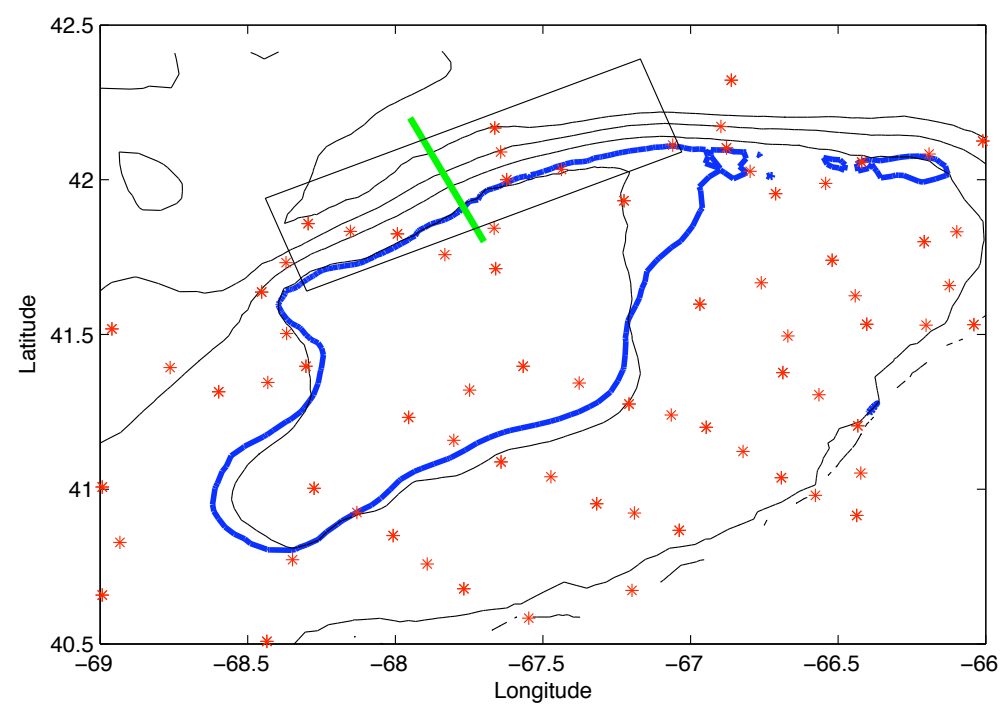

Figure 3: Station locations for the 1999 Broadscale Survey (OCEANUS 341, April 17-26) and the location of the model cross section (green line) across the Northern Flank of Georges Bank used for the comparisons presented in Fig 8 and Fig 9 below. Isobaths are plotted at 50, 100, 150, and $200 \mathrm{~m}$. The rectangular box indicates the approximate area surveyed by ENDEAVOR 324. A 2-D estimate of the mixing front location is shown in blue. The Georges Bank Buoy \# 44011 is at $41.1^{\circ} \mathrm{N}, 66.6^{\circ} \mathrm{W}$. The hindcast wind was measured there.

In Figure 5 we show the stations occupied during the cruise, generally proceeding from west to east. We have Towyo'd CTD data at these stations. Those numbered will be used to evaluate hydrographic forecast skill; the numbering increases chronologically. We also indicate the location of a standard model transect on Figure 5. 


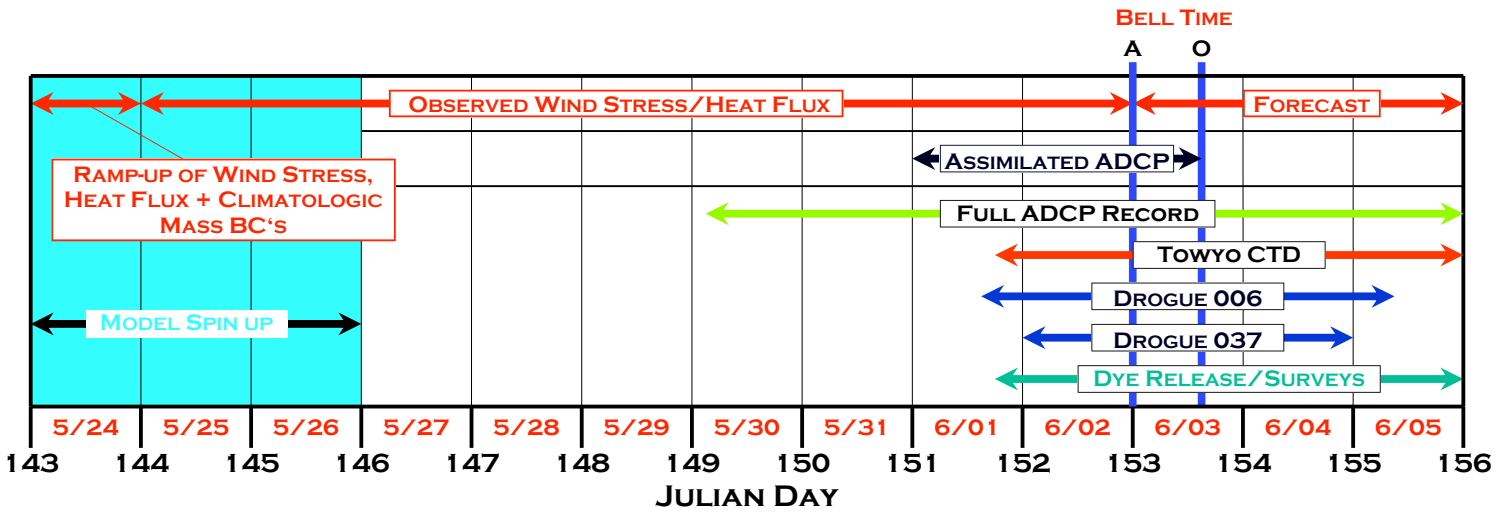

Figure 4: Timeline for model inputs, at-sea observations, data assimilation, and the forecast period. Hydrographic Initial Conditions (IC's) on 5/24 were estimated from observations in the period 4/17-26.

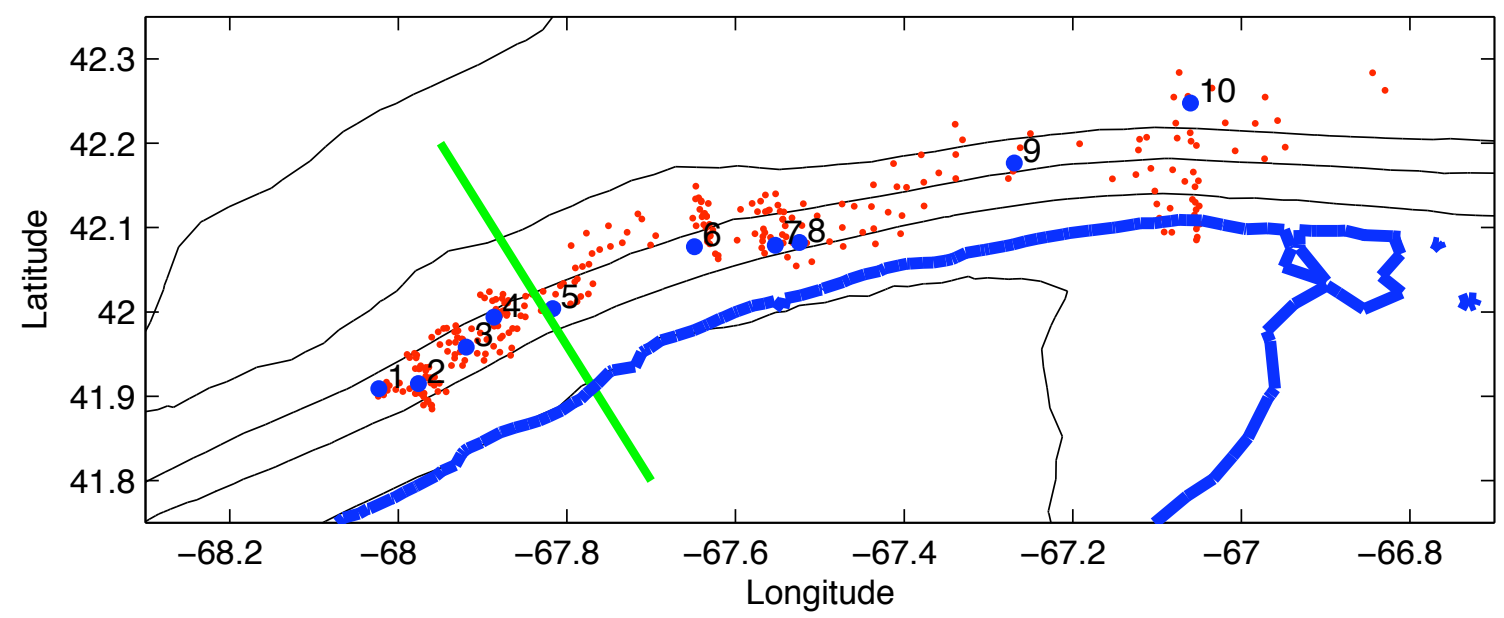

Figure 5: CTD profile locations for the Towyo hydrographic observations used for the comparisons presented in Fig 10. Superimposed is the location of the model cross section (green line) across the Northern Flank of Georges Bank used in 8 and 9 below. The Simpson-Hunter mixing line is also indicated (blue line), as in Figure 3. Bathymetric contours are in black, at 50, 100, 150, and $200 \mathrm{~m}$ as in all figures herein. 


\section{Dispersion Method}

To examine passive hydrodynamic dispersion in these fields we use a hybrid deterministic/stochastic approach. An ensemble of particles is moved in tidal time with deterministic individual motion given by the advective velocity from the simulation. Individual vertical motion is supplemented stochastically, with a random walk process keyed to the local vertical diffusivity. The ensemble of particles is large, permitting direct estimates of its distribution and moments.

\section{The Random Displacement Method for Diffusion}

We begin with a simple 1-D case of the diffusion of an initial top-hat distribution of particles under uniform diffusivity. The initial distribution, centered about the middle of the domain at $x=x_{c}$, is:

$$
C(x)=\left\{\begin{array}{cc}
C_{o} & -\frac{b}{2} \leq\left|x-x_{c}\right| \leq \frac{b}{2} \\
0 & \text { otherwise }
\end{array}\right.
$$

The analytic solution to the diffusion equation for these initial conditions is well-known (e.g. Csanady [6]):

$$
C(x)=\frac{C_{o}}{2}\left[\operatorname{erf}\left(\frac{\frac{b}{2}+\left(x-x_{c}\right)}{2 \sqrt{D t}}\right)+\operatorname{erf}\left(\frac{\frac{b}{2}-\left(x-x_{c}\right)}{2 \sqrt{D t}}\right)\right]
$$

Applying Lagrangian methods to simulate the diffusion of a collection of individual particles requires a model for the random walk. One approach is the naive one that allows each particle to execute a series of independent random steps that are directly scaled by the local diffusivity and the time step (Skellam, [40]; Csanady, [6]; Okubo, [34]; Visser, [43]). To match the diffusive scales, this random walk model takes the form:

$$
x(t+\delta t)=x(t)+R \sqrt{2 D \delta t / \sigma^{2}}
$$

where $D$ is the diffusivity at the particle position, $\delta t$ is the time step and $\mathrm{R}$ is a random variable with zero mean and variance $\sigma^{2}$. Applying this model, assuming a uniform probability distribution for the random variable $R$ (for $-1<R<+1$ ), to the above problem and integrating in time shows that the random walk model effectively captures the temporal evolution (Fig. 6).

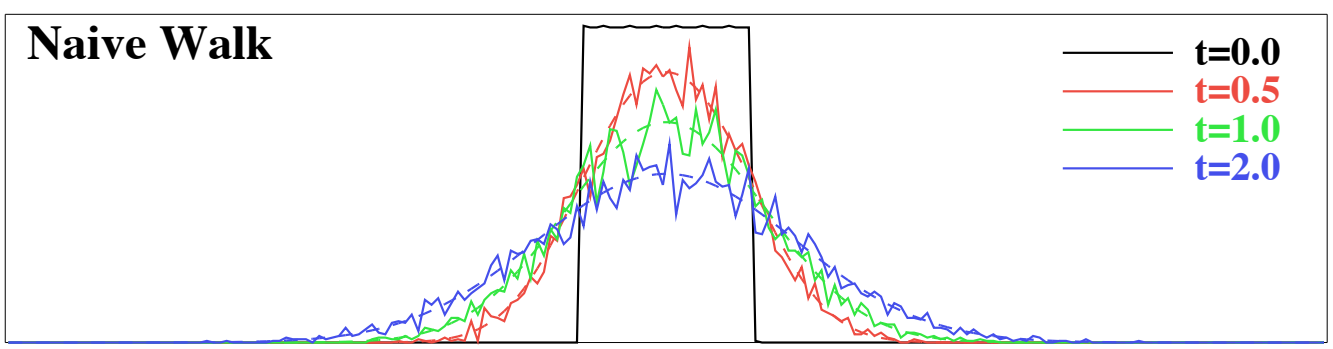

Figure 6: Random walk solution (solid lines) vs analytic (dashed) for the diffusion of an initial top-hat particle distribution under uniform diffusivity (non-dimensional). 
There is a problem when diffusivity is variable. It has been shown (e.g. Visser [43]) that naively applying a random walk using the local value of the diffusivity alone, leads to an artificial build-up of particles in regions of low diffusivity. Effectively, particles that randomly walk away from high diffusivity toward low diffusivity move farther on average than those moving the other direction. In order to avoid this difficulty, it is necessary to account for $\nabla D$, by introducing a pseudo-advective term that balances this artificial drift. Following Visser ([43]) a corrected random walk consistent with the diffusion equation can be derived and in 1-D is given by:

$$
\begin{aligned}
x(t+\delta t) & =x(t)+\left.\frac{\partial D}{\partial x}\right|_{x(t)} \delta t+R \sqrt{2 D\left(x^{*}\right) \delta t / \sigma^{2}} \\
x^{*} & =x(t)+\left.\frac{1}{2} \frac{\partial D}{\partial x}\right|_{x(t)} \delta t
\end{aligned}
$$

In addition to adding the pseudo-advective term, $\frac{\partial D}{\partial x} \delta t$, the diffusivity in the random walk is shifted in the direction of the local diffusivity gradient. To see the effect of neglecting to correct for the artificial drift, again consider the top-hat particle distribution but now diffusing under a parabolic diffusivity profile. The time evolution of the Eulerian solution along with the associated random walk solutions for this case are shown in Figure 7. The effect of the bias in the non-gradient corrected (naive) random walk (left panel) toward particle build-up in low diffusivity regions here manifests itself in the random walk simulation as an apparent time lag with respect to the numerical solution. Therefore, an initial patch of Lagrangian particles in the naive walk model would appear to diffuse too slowly. By comparison, the gradient-corrected random walk model (right panel) has no significant difficulty in simulating the diffusion correctly. The random walk model for diffusion can be easily generalized to anisotropic diffusivity in both 2 and 3-D (Proehl and Lynch, [36]). Adding advection is straightforward.
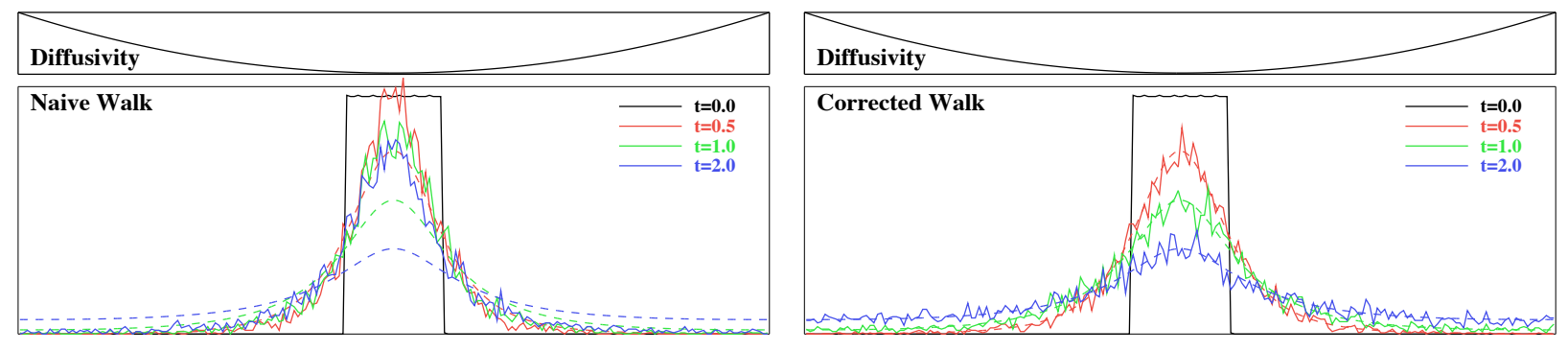

Figure 7: Temporal evolution of an initial tophat particle distribution for the naive (left) and gradient-corrected (right) random walk models. Dash lines: Eulerian; Solid lines: random walk. The parabolic diffusivity profile (top) varies by a factor of 100 from minimum to maximum to clearly demonstrate the gradient effect on the naive walk.

A related problem is the resolution of the diffusivity field. As Visser ([43]) points out the spatial criterion for using the corrected random walk model for diffusion modeling is that the profile of diffusivity be well approximated by

$$
D(x+\delta x)=D(x)+\delta x \frac{\partial D}{\partial x}
$$


over the range of possible turbulent displacements, $|\delta x|<\sqrt{2 D \delta t}$. This truncation of the Taylor series is reasonable provided:

$$
D \gg \frac{1}{2} \delta x^{2} \frac{\partial^{2} D}{\partial x^{2}} \quad \longrightarrow \quad \delta t \ll \min \left(1 / \frac{\partial^{2} D}{\partial x^{2}}\right)
$$

For Georges Bank simulations the minimum estimated value of $1 / \frac{\partial^{2} D}{\partial x^{2}}$ for vertical diffusion is roughly $4.5 \delta t$ and occurs in the very near bottom boundary layer on the Northern Flank. Therefore, we conclude that over the domain of interest the random displacement model with the first order derivative correction is applicable here.

\section{Ensemble Procedure}

Where appropriate we released ensembles of 10,000 particles within the simulated circulation fields, mimicking the tracer release shown in Figure 4. Particles were distributed about the central position $\left(41^{\circ} 54.6^{\prime} \mathrm{N}, 68^{\circ} 02.8 \mathrm{~W}\right)$ on 1 June 1999. An initial Gaussian distribution was assumed in the horizontal, with length scale estimated to be around $950 \mathrm{~m}$. All particles were released at the same depth, $20 \mathrm{~m}$. The Lagrangian timestep was $3 \mathrm{~min}$. Random vertical displacements were generated for each particle, based on the vertical diffusivity field computed by the circulation model. There was no horizontal random walk.

To isolate the effects of advection and vertical diffusion, we consider two primary modeling cases, one with advection alone the other with advection plus vertical diffusion. Our hypothesis is that the addition of vertical diffusive processes, coupled with 3-D velocity shear, generates realistic dispersion. We will examine the dynamics of the first and second moments of the distribution, with the latter representing the effective dispersion which is occurring.

Throughout we use the approximation

$$
\frac{d \sigma^{2}}{d t}=2 \kappa
$$

with $\sigma^{2}$ the ensemble variance (second moment of particle location about the mean) and $\kappa$ the effective dispersion coefficient. [8, $6,43,7,13]$. From the ensemble of particle positions, $\sigma^{2}$ is simply evaluated after every timestep; $\kappa$ is then estimated from the slope of the resulting timeseries. This is therefore a Lagrangian property of the ensemble. 


\section{Forecast Skill Assessment}

\section{Vertical Parameterization}

The model's ability to form sharp vertical temperature gradients due to surface heating is critical to proper simulation of the mixing front. This is especially so on the deep, stratified side of the front. There, bottom-generated tidal turbulence does not reach the mixed layer, and we depend on nearsurface mixing for the vertical distribution of atmospheric heating. Proper resolution and strength of the downward vertical mixing of heat is critical. This vertical turbulent mixing is closed in our simulations as an eddy diffusive process; it is parameterized through the diffusivity coefficient $\left(\kappa_{h}\right)$ which is obtained from the Mellor-Yamada level 2.5-level closure scheme [28, 29], with the Galperin and Blumberg extensions [9, 5]. It is well-known that the simulated bottom boundary layer is well-represented in this scheme, but that weakness may lie in the near-surface where mixing due to internal waves, wind waves, etc, and the surface boundary conditions on mixing length and heat input may not be fully captured. Accordingly, we employ a prescribed background (or basal) value of $\left(\kappa_{h}\right)$ that will govern the vertical mixing in regions of weak turbulence. A second free parameter is the vertical resolution. Clearly very small diffusivities can fail to perform if the mesh is too coarse. Lynch et al. [16] studied the resolution of the bottom boundary layer, concluding that with a graded vertical mesh, as few as 21 vertical nodes with near-boundary resolution $1 \mathrm{~m}$ was adequate. Here we employ the same sinusoidally stretched vertical meshing, with $1 \mathrm{~m}$ resolution at surface and bottom. The total number of vertical nodes $N Z$ constitutes the free parameter. As in the case of vertical viscosity, we anticipate that the limiting demands on vertical meshing may occur near the surface on the deep stratified side of the front.

Consequently, we performed a series of model experiments to determine the appropriate basal diffusivity $\left(\kappa_{\min }\right)$ and the necessary vertical resolution $N Z$. Simulations were run for $\kappa_{\min }$ ranging from $2 \times 10^{-5}$ to $2 \times 10^{-3} \mathrm{~m}^{2} / \mathrm{s}$, and for a doubled vertical resolution $(N Z=42)$ over that typically utilized for Georges Bank simulations.

In Figure 8 we present a set of tidally-averaged temperature sections across the northern flank. The high basal diffusivity does not produce a realistic thermocline and we reject this as a parameter choice. The simulation is over-mixing the heat input. Decreasing $\kappa_{\min }$ by an order of magnitude [from $2 \times 10^{-3} \mathrm{~m}^{2} / \mathrm{s}$ (top-left) to $2 \times 10^{-4} \mathrm{~m}^{2} / \mathrm{s}$ (top-right)] produces a realistic temperature field structure as usually seen in observations near the front, with important implications for the strength and structure of the along-front jet. Reducing the basal diffusivity by another order of magnitude [to $2 \times 10^{-5} \mathrm{~m}^{2} / \mathrm{s}$ (bottom-left)] yields little further change in the structure of the temperature field, but the surface waters are $1-2^{\circ} \mathrm{C}$ warmer due to the reduced vertical diffusion of heat.

In the lower right panel of Figure 8 we present the tidally-averaged, cross-bank temperature section from a simulation with a doubled vertical resolution $(N Z=42$ sinusoidally spaced $\sigma$ levels $)$. Comparison to the lower resolution result (top-right) shows very little difference suggesting that for the temperature field, the lower vertical resolution may be sufficient.

The extreme run with low diffusivity and high resolution (not shown) exaggerated the surface heat trapping reported above with $N Z=21$ (Figure 8, lower left), reaching surface temperatures in excess of 40 degrees. Based on this we reject the low diffusivity/ high resolution possibility.

In Figure 9 we present the results for the tidally-averaged, along-bank flow in the same four panel format as for temperature (Fig 8). All four cases show the presence of the along-bank shelfbreak 

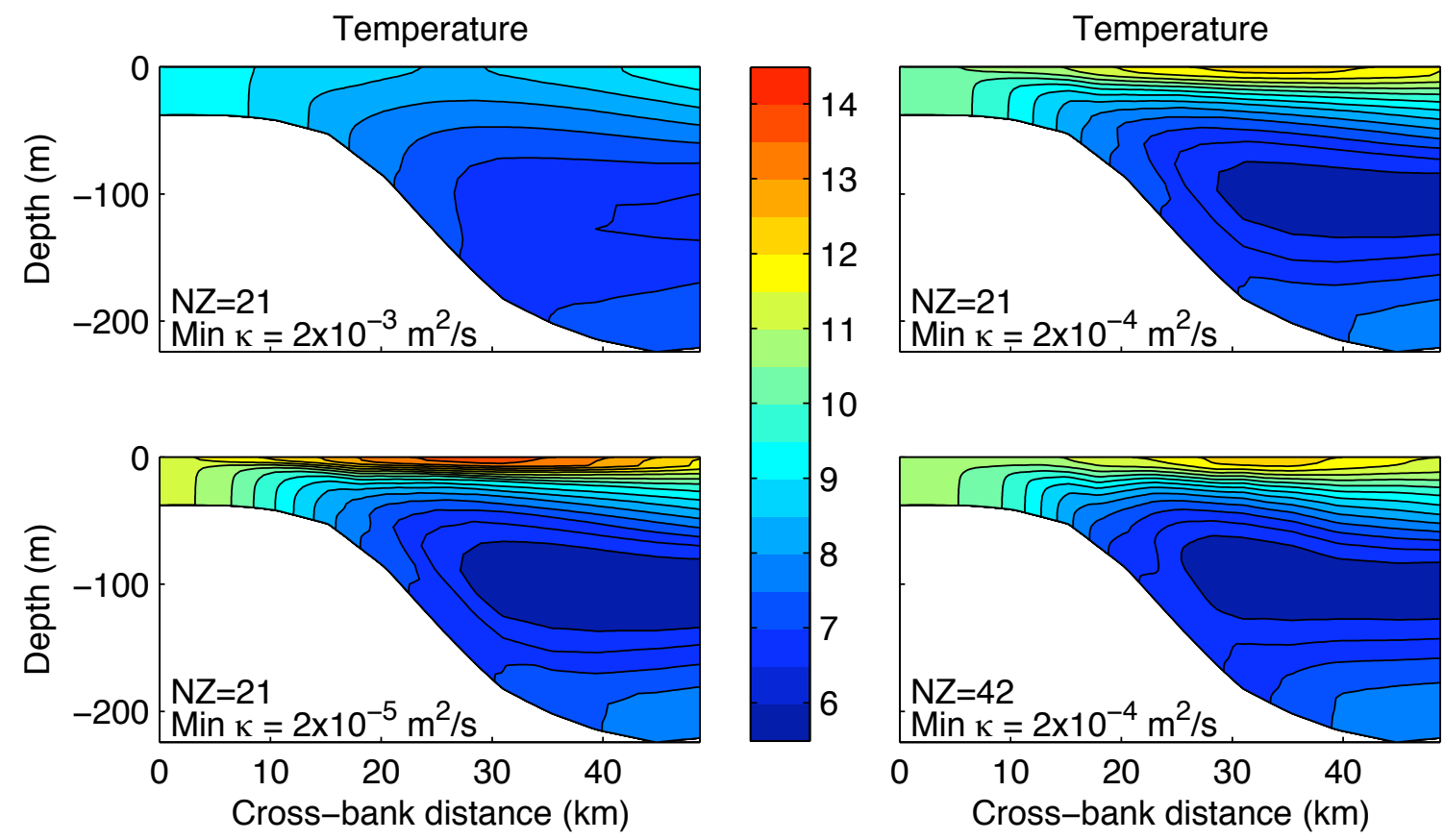

Figure 8: Temperature section (tidally averaged) across the Northern Flank as a function of basal model diffusivity and vertical resolution. Clockwise from top-left: High basal diffusivity $\left(\kappa_{\min }\right)$; Medium diffusivity; Medium diffusivity, high vertical resolution; Low diffusivity. The section location is plotted in Figure 3

jet. In the higher basal diffusivity case (upper left) the jet is broader and possesses a subsurface maximum with peak speed roughly $19 \mathrm{~cm} / \mathrm{s}$. As the basal diffusivity decreases the along-bank jet strengthens, becomes narrower and more surface intensified, reaching $29 \mathrm{~cm} / \mathrm{s}$ in the moderate case (top right) and $33 \mathrm{~cm} / \mathrm{s}$ in the lowest basal diffusivity case (lower left). The observed around bank circulation varies seasonally on the northern flank ranging from around $20 \mathrm{~cm} / \mathrm{s}$ in winter to a peak in the vicinity of $40 \mathrm{~cm} / \mathrm{s}$ during summer (Butman et al., 1987). Model values of around $30 \mathrm{~cm} / \mathrm{s}$ in late May - early June for the two lower diffusivity thresholds then are in the range of observational evidence.

Comparing the effect of vertical resolution (upper right to lower right) shows minor changes in structure and intensity of the frontal jet $(29 \mathrm{~cm} / \mathrm{s}$ for the lower resolution case versus $28 \mathrm{~cm} / \mathrm{s}$ in the higher). More important is the introduction of the core of weak $(4 \mathrm{~cm} / \mathrm{s})$ southwestward flow counter to the frontal jet, in or beneath the pycnocline, and centered at around $40 \mathrm{~km}$ off bank. In addition to its better resolution and higher speed, this core appears to have moved toward the Bank in the higher resolution case. Note that the transect in question terminates at the deep midpoint of Franklin Basin, the narrow southwestward extension of Georges Basin (Figure 1). We are apparently sampling a weak cyclonic circulation feature on its northward flank. As this feature is occurring in deep $(200 \mathrm{~m})$ water, we expect that resolution is likely important here and favor the higher resolution case.

The conclusion of this sensitivity study is our selection of the intermediate diffusivity, high resolution case for further study: $\kappa_{\min }=2 \times 10^{-4} \mathrm{~m}^{2} / s, N Z=42$. We refer to this as the "High 
Resolution" case below. It is interesting to note that Horne et al. [11] estimated comparable values for tidal-time vertical diffusivity, 1. $-10 . \times 10^{-4} \mathrm{~m}^{2} / \mathrm{s}$, for near-surface, stratified waters on the Northeast Peak, based on turbulence measurements. Ullman et al. [42] made higher estimates, $\times 10^{-3} \rightarrow \times 10^{-1} \mathrm{~m}^{2} / \mathrm{s}$, which include the mixed side of the front. Houghton [12] estimated vertical diffusivity in the bottom boundary layers of the South Flank and Northeast Peak and obtained $1.4-2.5 \times 10^{-3} \mathrm{~m}^{2} / \mathrm{s}$, based on dye injections. Our conclusions about basal values are consistent with the lower limits of these observations. In the simulations, the lower basal value, $\kappa_{\text {min }}=2 \times 10^{-4} \mathrm{~m}^{2} / \mathrm{s}$, constrains Eulerian diffusion on the stratified side in the absence of more significant modeled turbulence; higher values generated by the level 2.5 closure govern where tidal shear is more pronounced.

It is important to avoid overgeneralizing this conclusion. There are many open issues with modeling the turbulence in the near-surface layer. Our results suggest that near-surface heat diffusion needs to be enhanced over the model-generated turbulence, off-bank. But we need to guard against extrapolating this background value beneath the air-sea exchange zone. Observed diapycnal dispersion of the dye patch in the present experiment gives a value for the diapycnal diffusivity of around $3 \times 10^{-5} \mathrm{~m}^{2} / \mathrm{s}$ (Ledwell and Churchill, in prep.). Even lower diapycnal diffusivities of $10^{-6}$ to $10^{-5} \mathrm{~m}^{2} / \mathrm{s}$ were measured with dye releases on the shelf south of New England at stratifications similar to that in the dye patch here [14]. Our higher estimate of a basal value here is connected with heat and turbulence penetration at the surface, and its discrete parameterization and resolution. We reserve judgement about vertical diffusivities in and below the pycnocline, off-bank where modeled turbulence is low. Accordingly, for ensemble calculations of tracer transport (initialized at $20 \mathrm{~m}$ depth), we retain the level 2.5 closure as is, not subject to the basal value.
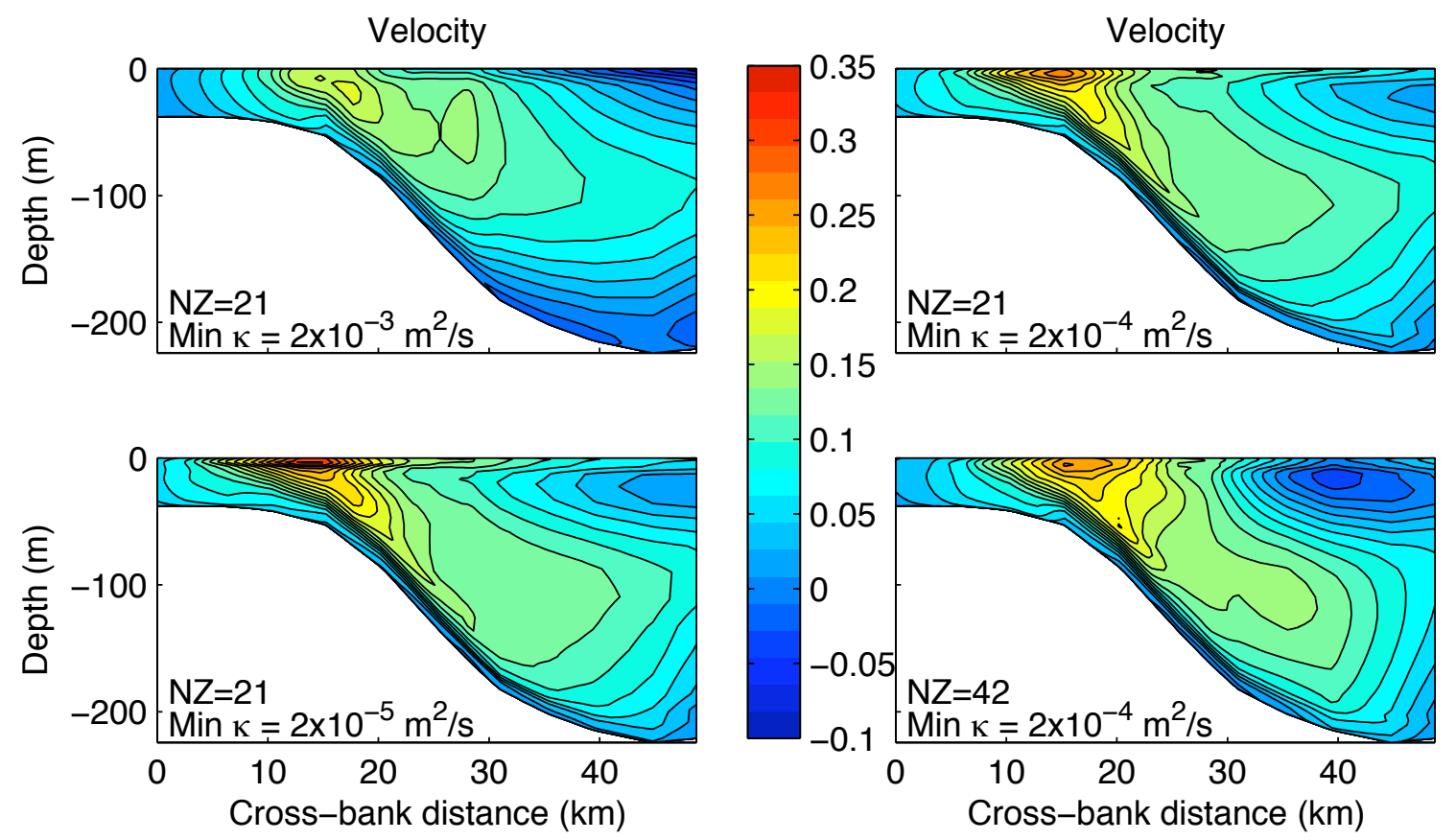

Figure 9: Velocity section (tidally averaged) across the Northern Flank as a function of basal model diffusivity and vertical resolution. Same arrangement as figure 8. 


\section{Fidelity of the Thermal Field}

To more carefully assess model skill we conduct a direct, model-data comparison for the hydrographic observations from the CTD onboard the Towyo sampler. Temperature largely controls density here, so we concentrate on that. Fig 4 gives the timing of these observations, which were not assimilated into the model. The modeled thermal field is initialized from the previous Broadscale Survey (Figure 3), about 5 weeks prior to the Towyo data. ${ }^{1}$ Modeled physical processes, forced by observed surface heat flux, are responsible for the subsequent thermal evolution. Thus the joint effects of the non-synoptic and tidally-aliased initialization, the atmospheric flux data input, and the internally-computed heat transport, all contribute to model performance here.

The Towyo operation generally sampled along-isobath, on the stratified side of the front. The stations used are numbered as in Figure 5. These stations bracket the location of the tidallyaveraged cross-sections shown above in Figures 8 and 9.
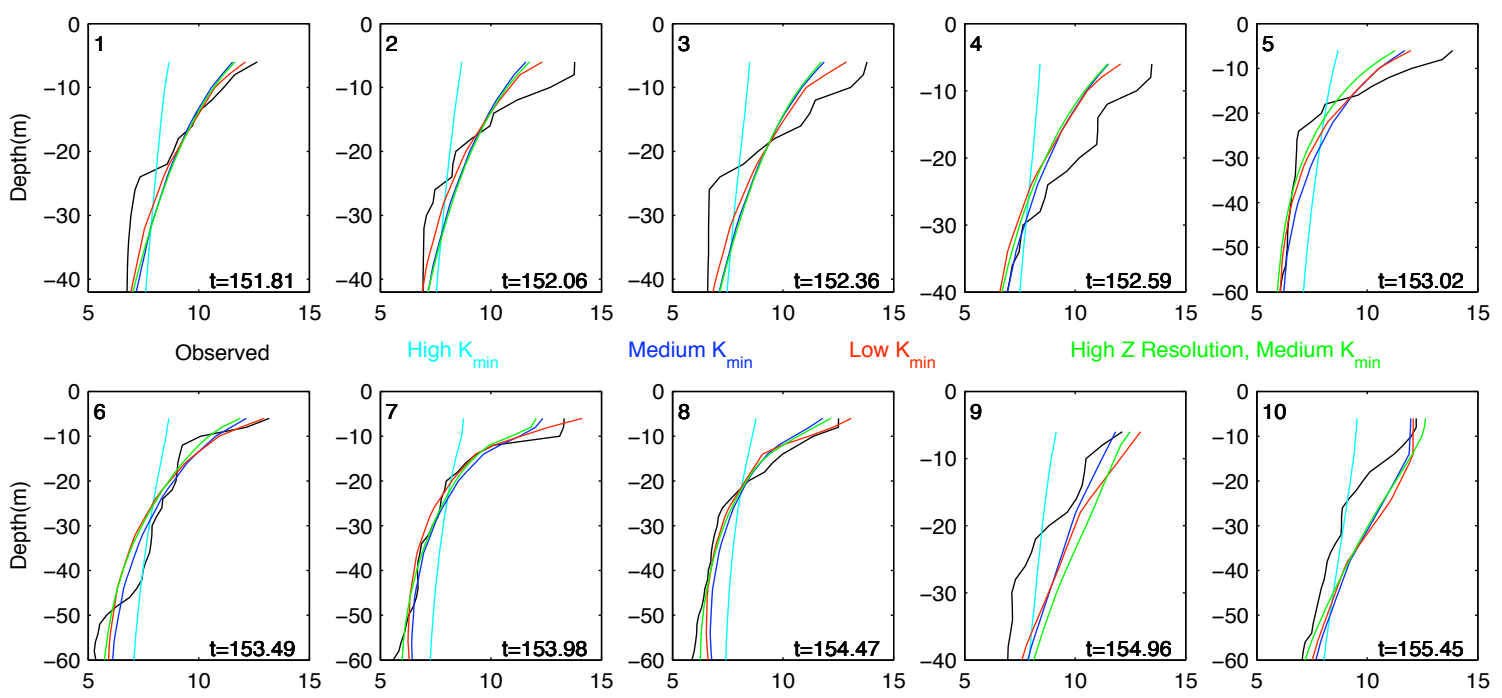

Figure 10: Temperature profiles from the Towyo survey at stations numbered in Fig 5 and model results for the four model simulations.

In Figure 10 we present computed profiles for the four model cases, superimposed upon the Towyo observations. It is apparent that except for the high basal diffusivity case, the vertical structure of the model temperature field is not very sensitive to the range of parameters studied here. This is consistent with the previous Figure 8. It is clear from the nearly isothermal profiles, that the high basal diffusivity case is much too diffusive. With respect to the remaining three cases the model does a reasonable job of simulating the observed vertical temperature structure in the region of the Northeast Peak (profiles 6-8), but has difficulty in the upper ocean to the west (profiles 2-5) underestimating the near-surface $(5-20 \mathrm{~m})$ thermal stratification.

The statistical results using all of the Towyo CTD profiles are presented in Table 1 . The visual improvement seen from the reduction of the basal diffusivity from $2 \times 10^{-3} \mathrm{~m}^{2} / \mathrm{s}$ to $2 \times 10^{-4} \mathrm{~m}^{2} / \mathrm{s}$

\footnotetext{
${ }^{1}$ The survey itself took about 10 days to complete.
} 


\begin{tabular}{|c|c|c|c|c|c|c|c|c|c|}
\hline \multirow[b]{2}{*}{ Case Name } & \multirow[b]{2}{*}{$\bar{T}\left({ }^{\circ} \mathrm{C}\right)$} & \multirow[b]{2}{*}{$\bar{S}(\%)$} & \multirow[b]{2}{*}{$\overline{\sigma_{t}}\left(\mathrm{~kg} / \mathrm{m}^{3}\right)$} & \multicolumn{2}{|c|}{$\Delta \mathrm{T}\left({ }^{\circ} \mathrm{C}\right)$} & \multicolumn{2}{|c|}{$\Delta S(\%)$} & \multicolumn{2}{|c|}{$\Delta \sigma_{t}\left(\mathrm{~kg} / \mathrm{m}^{3}\right)$} \\
\hline & & & & Mean & $\sigma$ & Mean & $\sigma$ & Mean & $\sigma$ \\
\hline Observed & 8.403 & 32.452 & 25.192 & - & - & - & - & - & - \\
\hline High $\kappa_{m i n}$ & 8.053 & 32.658 & 25.426 & 0.350 & 1.742 & -0.206 & 0.106 & -0.234 & 0.314 \\
\hline Moderate $\kappa_{\text {min }}$ & 8.595 & 32.485 & 25.198 & -0.192 & 1.042 & -0.033 & 0.114 & -0.006 & 0.202 \\
\hline Low $\kappa_{\min }$ & 8.529 & 32.467 & 25.188 & -0.126 & 1.037 & -0.015 & 0.127 & 0.004 & 0.211 \\
\hline High Z Res. & 8.538 & 32.484 & 25.203 & -0.135 & 1.078 & -0.032 & 0.121 & -0.012 & 0.212 \\
\hline
\end{tabular}

Table 1: Hydrographic Data, Model, and Misfit (DataModel) statistics for the 4 model cases using the data and stations from the Towyo CTD. For the misfits, $\sigma$ is the standard deviation about the mean misfit.

shows up as a significant improvement in the ability to capture mean temperature, salinity and density. Further reduction leads to some improvement but as expected from figure 10 the effect isn't dramatic. It is interesting to note that for all but the high diffusivity case the model results consistently show a slight warm, salty bias $\left(<0.2{ }^{\circ} C, \sim 0.3 \%\right.$. These are small biases and they are unlikely to be dynamically important here; we have made no effort to isolate their origins. They are also small compared with the large variances in the data (not shown).

As a bottom line assessment, the model-data misfit is roughly $1^{\circ} \mathrm{C}$ RMS and $0.14^{\circ} \mathrm{C}$ mean, for instantaneous, depth-dependent temperature. This is the result of initial conditions measured nonsynoptically a month prior to initialization; plus observed surface heating and simulated internal redistribution for 9-12 days. 


\section{Velocity Field}

Next we examine simulation skill with respect to velocity. From the point of view of ecological transport, the relevant quantity is the tidally-averaged flow and the effective dispersion on that timescale. However the ADCP data are sampled instantaneously on a moving platform. We expect these data to contain rotary tidal motion in the range $0-1 \mathrm{~m} / \mathrm{s}$ and a directed subtidal contribution in the range $0-.3 \mathrm{~m} / \mathrm{s}$. The only ADCP processing we perform is vertical vector averaging over the interval actually sampled; that is the data product which is assimilated in order to infer the barotropic open boundary conditions [24]. Model output is processed in the same way. We use the symbol $\overline{\mathbf{V}}$ for this partial vertical average.

The $\overline{\mathbf{V}}$ comparisons appear in Figure 11. The misfit is of order $5-10 \mathrm{~cm} / \mathrm{s}$, and is generally largest off-bank. It is somewhat insensitive to the strength of the basal diffusivity but improves markedly as the vertical resolution is doubled. Close inspection reveals that most of the disagreement is related to flow direction rather than magnitude. We know from experience that compass errors in the instrumentation can be problematical, as can model-data timing mistakes, especially where tides are significant. Also, small-scale local bathymetric variations, which are smoothed in model bathymetry, contribute to variance in vector differences.

Statistical summaries in Tables 2 and 3 show both vertically-averaged and point (depth-dependent) metrics. In particular the point metric shows good skill and the same primary effect of resolution as is evident in the vertically averaged plots and statistics. Recall that the $\overline{\mathbf{V}}$ data are assimilated up to the oceanic bell; the more detailed $\mathbf{V}(z)$ are not.

In Table 3 we separate these misfits into hindcast and forecast. The hindcast misfit field was minimized in a least-squares sense by boundary condition adjustment; the forecast field was not fit.
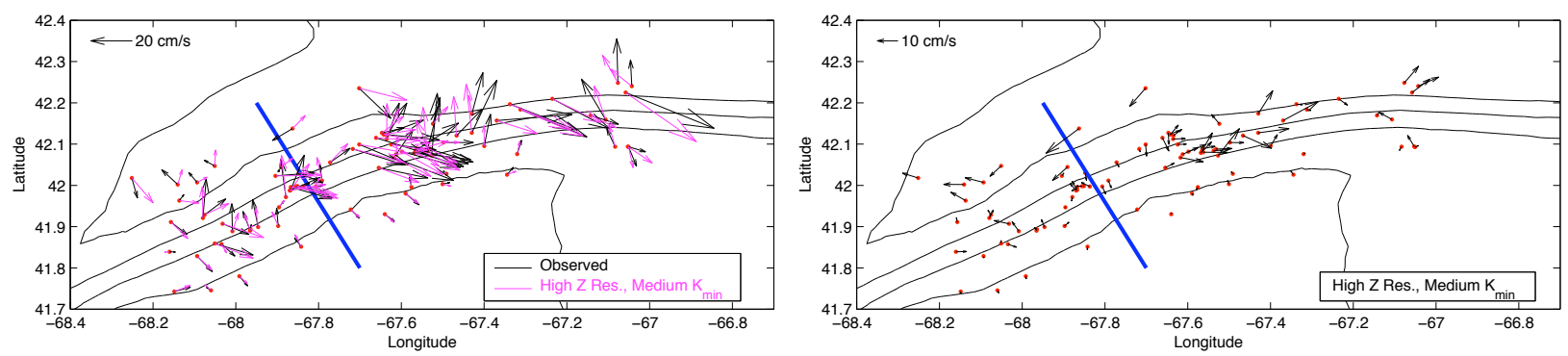

Figure 11: Vertically integrated ADCP data and coincident model predictions (left) and the model-data misfit (vector differences, right) for the high-resolution, intermediate diffusivity case. To improve legibility only every other ADCP profile is displayed. 


\begin{tabular}{|ccc|ccc|}
\hline \multicolumn{4}{|c|}{ ADCP Observations (cm/s) } \\
$\overline{\mathbf{V}}$ & & \multicolumn{3}{c|}{$\mathrm{V}(z)$} \\
\hline Mean & $\sigma$ & Max & Mean & $\sigma$ & Max \\
\hline 15.99 & 9.51 & 46.12 & 17.54 & 18.75 & 101.39 \\
\hline
\end{tabular}

Table 2: Speed statistics for the shipboard ADCP observations. The barotropic velocity is vector-averaged over the actual vertical sampling interval. $\sigma$ is the standard deviation about the mean.

\begin{tabular}{c|cc|cc|}
\cline { 2 - 5 } & \multicolumn{4}{|c|}{ ADCP Misfit (cm/s) } \\
& \multicolumn{2}{|c|}{ V $(z)$} \\
\hline Case Name & Pre-Bell & Post-Bell & Pre-Bell & Post-Bell \\
\hline High $\kappa_{\min }$ & 9.46 & 15.45 & 14.21 & 21.90 \\
Moderate $\kappa_{\min }$ & 10.37 & 16.03 & 15.45 & 22.96 \\
Low $\kappa_{\text {min }}$ & 10.39 & 16.46 & 15.37 & 23.38 \\
High Z Res. & 4.77 & 8.72 & 10.07 & 16.36 \\
\hline
\end{tabular}

Table 3: RMS velocity misfit metrics for the four model cases. The data are divided into active (pre-oceanic bell) and passive (post-bell). The vertically averaged data, $\overline{\mathbf{V}}$, are assimilated pre-bell. The individual observations $\mathbf{V}(z)$ are not assimilated individually. These misfits are therefore higher. All runs use the winds as forecast at sea. 


\section{Drifters}

During the cruise, fixed depth drifters were released and tracked for $\mathrm{O}(5$ days). We concentrate on the two which are near the front in the timeframe given in Figure 4. Both were drogued to $19 \mathrm{~m}$ and placed initially in the pycnocline close to the mixing front (on the stratified side), a few hours apart. Unlike the Eulerian ADCP comparisons, drifter displacements provide a complicated Lagrangian integral metric of the flow field, its initial and evolving uncertainty, and its unresolved eddies. No displacement data were assimilated.

We have no hydraulic model for these drifters; instead they are assumed to respond instantaneously to the local horizontal velocity field, with depth fixed; and without any measurement error. The simulation fields are sampled in that way in order to integrate Lagrangian misfits. Clearly there are drifter dynamics related to oceanic and atmospheric influences which are not captured here (e.g. Geyer [10], Niiler et al. [33], Mariano et al. [25]).

In the upper panels of Figure 12 we present the fixed-depth trajectories for modeled and observed drifters. The effect of the strong tidal motion manifests itself in the drifter trajectories in the form of loops which grow stronger as the drifters move into shallower water. Superimposed upon the strong tidal motion is a net northeastward drift associated with the tidally-rectified, anti-cyclonic circulation around the bank. It is obvious from both upper panels that the model drifters have a strong tendency to move up onto the bank whereas the observed drifters tended slightly off-bank. ${ }^{2}$ This on-bank bias in velocity was not apparent from the previous ADCP comparison. The lower panels of Figure 12 show the separation distance between the simulated and observed trajectories as a function of time. As with previous comparisons, the increase in vertical resolution (not shown) improved the result.

Linear-in-time fits of this separation data are shown in Figure 12, and the separation rates are presented in Table 4. For the high resolution case the rates are 4.86 and $7.43 \mathrm{~km} / \mathrm{d}$ for the two drifters, assuming zero initial separation. It is clear from Figure 12 that in both cases the difference in cross-bank displacement is the most important. The along-bank separation is small for Drifter 006; for Drifter 037 the along- and cross-bank misfits contribute about equally. In [22] we noted that forecast drifter separation rates could be as low as $3.4 \mathrm{~km} / \mathrm{d}$ for this system, based on the accumulation of numerous forecasts on the North and South Flanks of the Bank. These particular data are not inconsistent with that. But, they suggest improvement is possible.

The Lagrangian separation rates are are also broadly consistent with the velocity misfits. The Eulerian results showed that there are significant directional misfits to the ADCP $\overline{\mathbf{V}}$ data, but these errors did not seem to be systematically on bank as the drifter trajectory misfits suggest. However the Eulerian $\mathbf{V}(z)$ misfits are necessarily larger that the $\overline{\mathbf{V}}$. Apparently, the Eulerian misfits nearer the surface are biased toward an on-bank forecast error; and the Lagrangian integration of that bias is showing up in the drifter comparisons.

We see here that we have an ecologically significant difference in terms of predicted cross-frontal motion which the real drifters did not exhibit.

\footnotetext{
${ }^{2}$ In fact drifter 006 moved dramatically off bank and away from the simulation (about $10 \mathrm{~km}$ ) during the first day, and generally moved along-bank thereafter.
} 

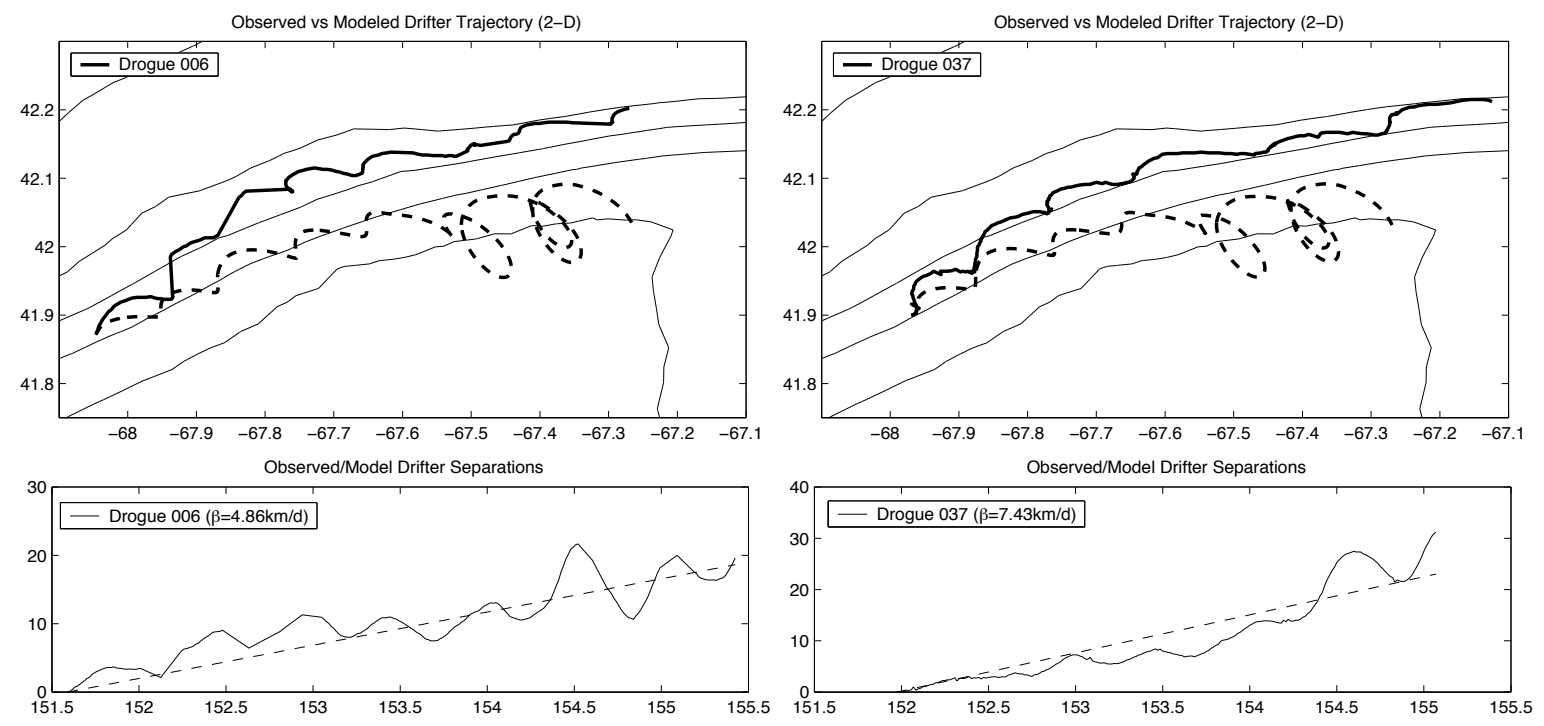

Figure 12: Top Panels - Comparison of two observed, fixeddepth drifter tracks (solid lines) with simulated fixed-depth drifters (dashed lines) for the "High Resolution" model configuration. Bottom Panels - Separation between simulated and observed drifters versus time; and the zero-intercept, least squares linear fit.

\begin{tabular}{cc|cccc|}
\cline { 3 - 6 } Drogue \# & \multicolumn{4}{|c|}{ Model Configuration } \\
\hline 006 & Fit Type & High $\kappa_{\min }$ & Moderate $\kappa_{\min }$ & Low $\kappa_{\min }$ & High Z Res. \\
& Best fit & 4.65 & 5.50 & 4.28 & 3.85 \\
& Zero intercept & 6.73 & 8.01 & 7.11 & 4.86 \\
\hline 037 & Best fit & 10.46 & 10.41 & 10.23 & 8.85 \\
& Zero intercept & 10.13 & 10.43 & 10.43 & 7.43 \\
\hline
\end{tabular}

Table 4: Linear separation rate $(\mathrm{km} / \mathrm{d})$ for the 4 model cases. The "Best fit" is in the linear least squares sense. The "zero intercept" result imposes an added constraint on the fit that the observed and modeled drifter are initially coincident. The rapid initial separation of 006 noted in the text calls into question the "zero intercept" assumption here. 


\section{Tracer Center of Mass}

Here and below we standardize the oceanic simulation at the "High Resolution" case from above.

For tracer ensembles, we compute either with pure 3-D advection ("nondiffusive"); or by adding vertical diffusion (random walk) from the level 2.5 vertical closure. This is referred to as the "diffusive case". As discussed above, we do not enforce a minimum basal diffusivity on these ensembles. Horizontal diffusion is zero in all cases.

The in-situ dye is sampled using a fluorometer mounted on a sled (the Towyo) which is towed while executing a series of up-down profiles across the dye patch. The vertical excursions are rapid enough to consider each up or down transit as a local vertical profile. Due to obvious space-time constraints, these data are neither synoptic nor complete. Their evaluation requires a fuller analysis in its own right, which is underway as a separate study (Ledwell and Churchill, in prep.). Here we concentrate only on estimating the center of mass of the dye.

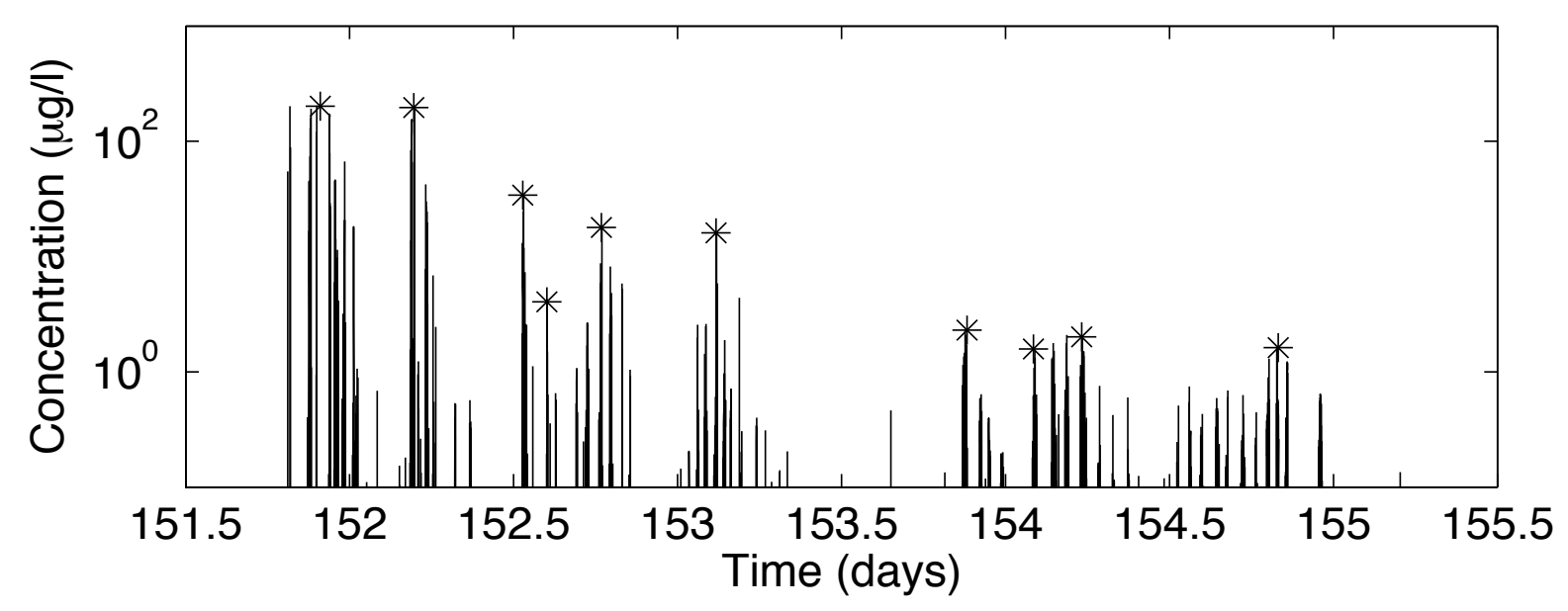

Figure 13: Time series of Towyo observations (vertical lines) showing the times identified as center of mass estimates (asterisks).

Figure 13 illustrates the sequential fluorescence data and our interpretation procedure. If an observation is the maximum observed within a moving 1.5 hour window, then its space-time location is considered an estimate of the dye center of mass. Small concentrations, below $1 \%$ of the overall maximum observed, are discarded. The trajectory so obtained appears in Figure 14 along with the two drifter trajectories. Centers of mass estimated from objective maps of the dye patch made recently agree with these estimates, within $3 \mathrm{~km}$. The sampling generally stayed on the stratified side of the front. (Figure 5.) Notice that this data generally ends before the hindcast and forecast wind products diverge.

The drifters generally provided good estimates of the dye location. Figure 15 indicates that particularly drifter 006 separated at only $0.58 \mathrm{~km} /$ day. Drifter 037 's separation rate was higher, $3.57 \mathrm{~km} /$ day.

Modeled centers of mass are plotted in Figure 16 for diffusive and non-diffusive ensembles. The separation rates are displayed in Figure 17. These separation rates are comparable to those between dye and drifter 037. But qualitatively they are different; 037 sped ahead of the dye, 
while the ensembles moved closer to the bank and were slower along-bank. Quantitatively, the rates $2.89-3.32 \mathrm{~km} /$ day are consistent with other data here, and with expectations. Significantly, the non-diffusive ensemble avoided some of the on-bank excursion which the diffusive ensemble experienced. (Below we show that this reflects an erroneous forecast wind event which produced on-bank Ekman drift, entraining part of the ensemble and producing a bimodal distribution.)

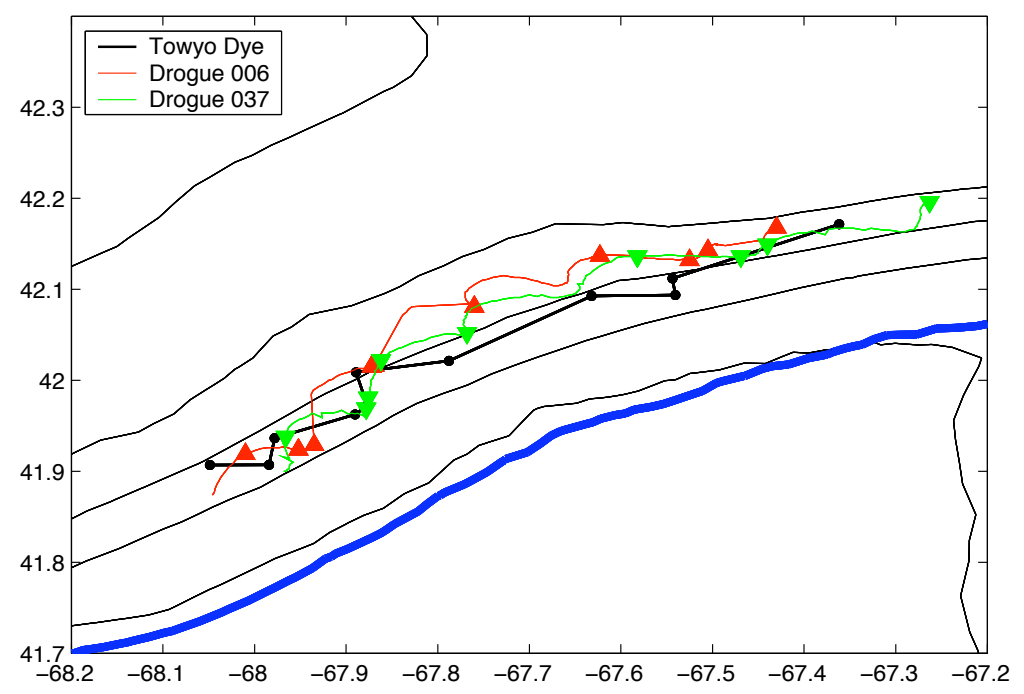

Figure 14: Observed dye center of mass and observed drifter trajectories. The markers indicate the time of peak observation from Figure 13. The thick blue line is the time-averaged Simpson-Hunter mixing front.

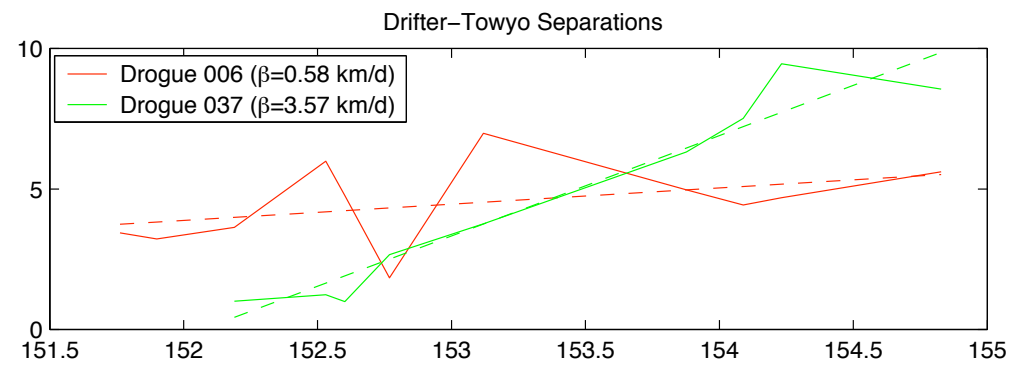

Figure 15: Separation distance versus time between estimated dye center of mass, and drifters. The least squares linear fits (dashed lines) with slope $\beta$ are superposed. 


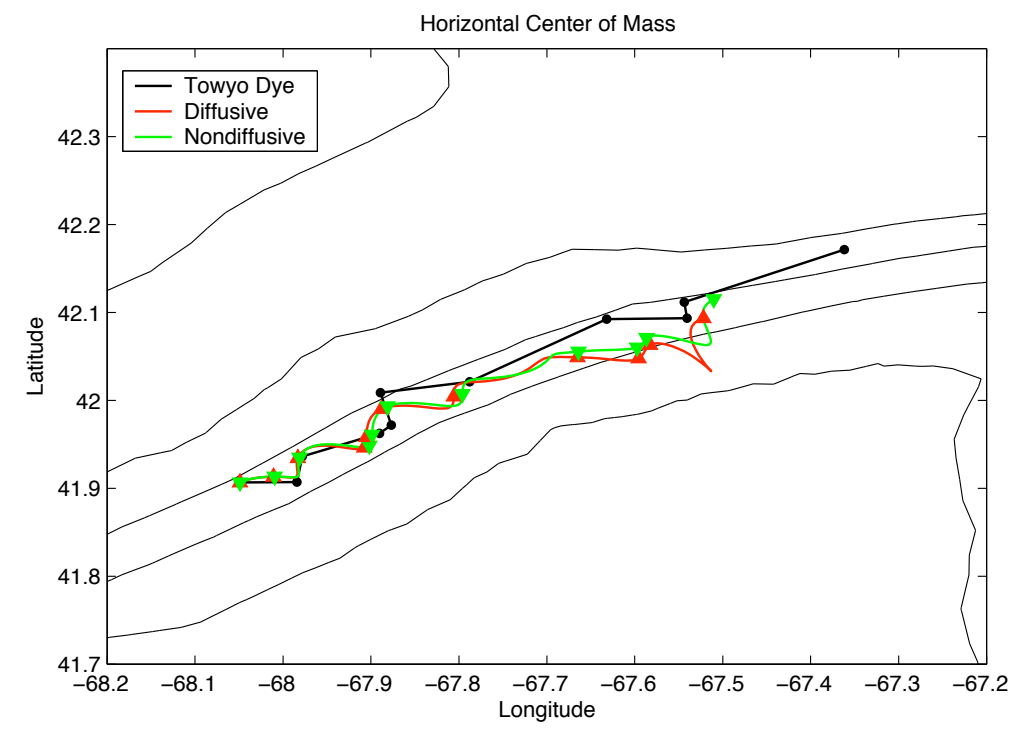

Figure 16: Computed Ensemble Centers and Observed Tracer Center. Markers indicate the time of observation of dye center. The ensemble trajectories are truncated at the last observation.

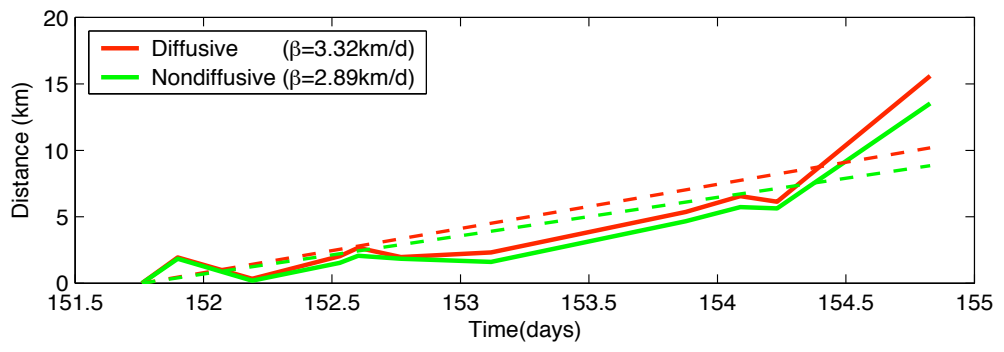

Figure 17: Separation distance between ensemble mean position and estimated dye center of mass, versus time. The least squares linear fits (dashed lines) with slope $\beta$ are superposed. 


\section{Dispersion and Ensemble Length Scales}

The depth histories of the center of mass for the diffusive and non-diffusive ensembles are not very different (Figure 18). The largest signal in both cases is tidal advection across the topography. During this process, the ensemble generally maintains relative position in the water column, as it moves on and off the bank. Related, the water column stretches and shrinks. This advective excursion reaches $20 \mathrm{~m}$ by the end of the simulation. Both cases show some deepening on the last day.

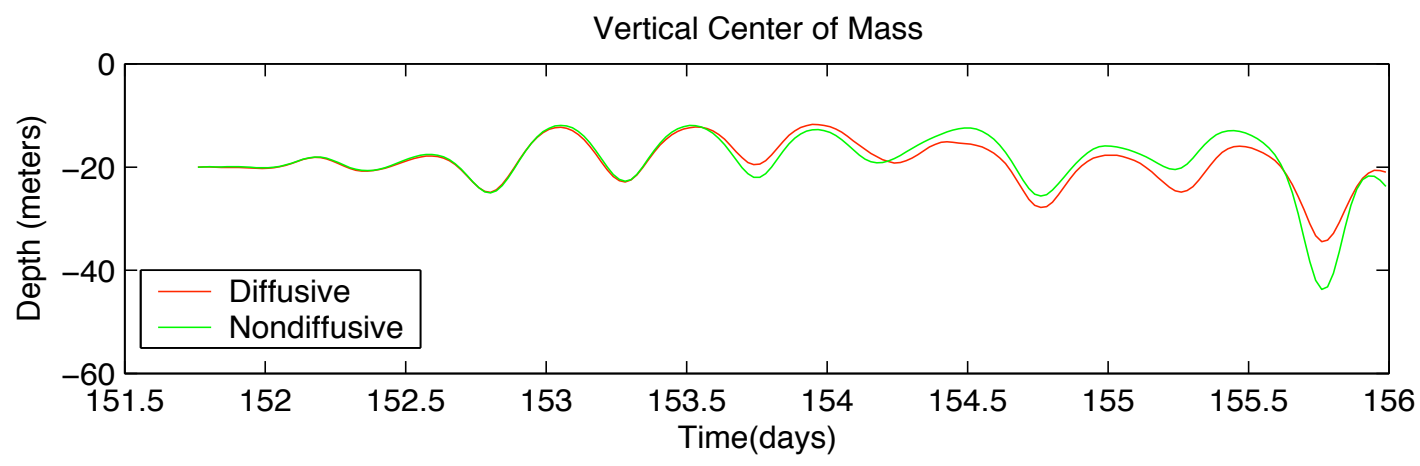

Figure 18: Vertical center of mass for the diffusive and nondiffusive forecast ensembles.

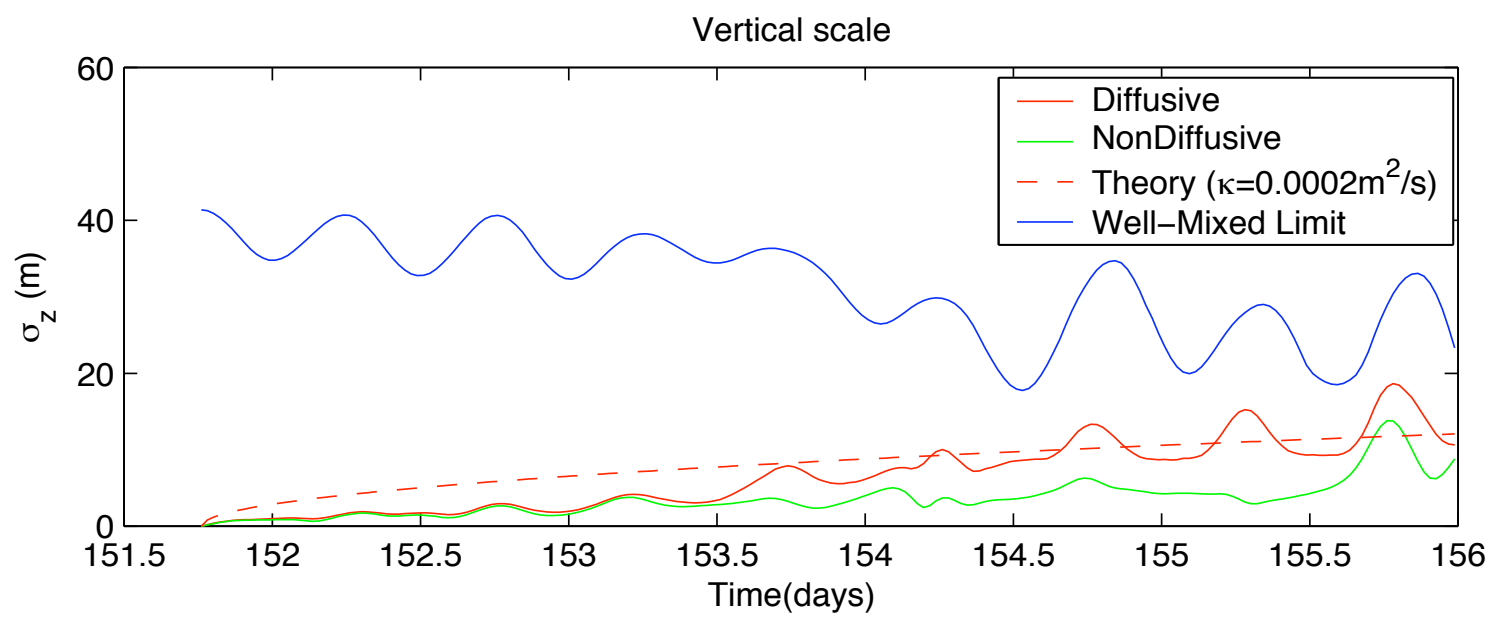

Figure 19: Vertical standard deviation of the diffusive and non-diffusive forecast ensembles. Superimposed are two theoretical length scales: i) for a purely diffusing ensemble initiated at zero variance; and ii) for a vertically well-mixed ensemble $\sigma_{z}^{2}=\frac{1}{3}\left(\frac{H}{2}\right)^{2}$ where $H$ is the depth under the ensemble center of mass. The latter case is the upper limit in a finite water column. 


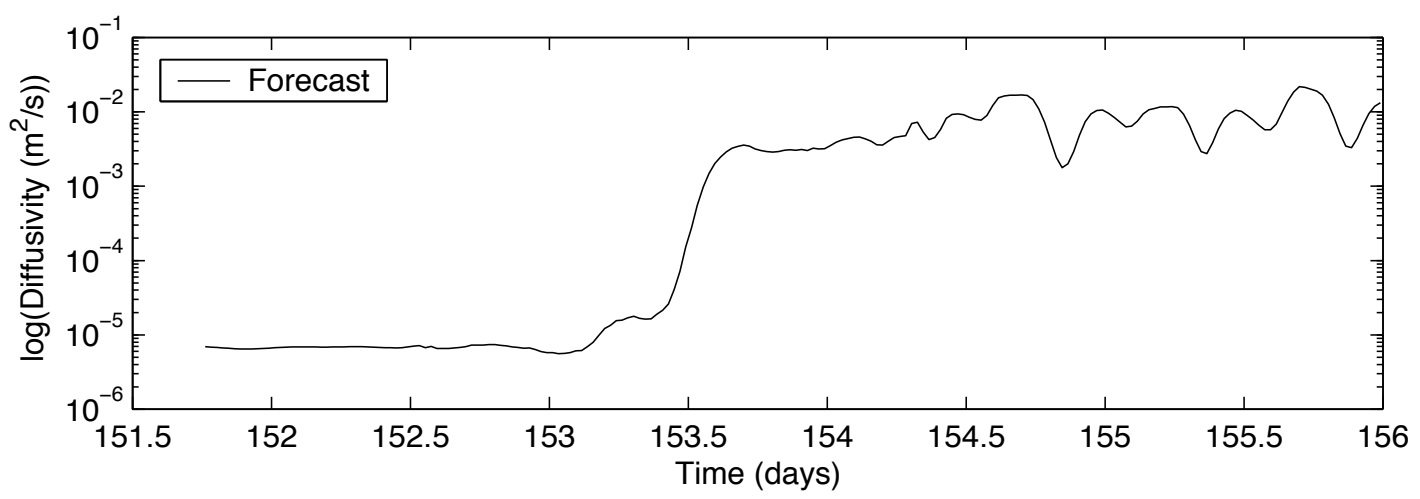

Figure 20: Ensemble mean vertical diffusivity, versus time, for the diffusive forecast. The diffusivity field is computed by the Level 2.5 closure on the finite element grid, then sampled by each Lagrangian particle, then averaged over the whole ensemble.

The vertical size of the ensembles are virtually the same until day 153.5 (Figure 19), and small compared to the reference for $.0002 \mathrm{~m}^{2} / \mathrm{s}$. Both ensembles are off-bank and in more quiescent water. At day 153.5 the diffusive scale begins to grow, while the nondiffusive scale remains smaller by a factor of 2 or 3 . In this period the ensemble is shoaling (the well-mixed limit is proportional to the ensemble-mean depth). Near the end of the simulation (last half day) the nondiffusive scale also shows some growth, suggesting that the late growth in the diffusive ensemble is advective in origin. The gap between the ensemble variances and the limiting well mixed variance begins to close at the end of the simulation, as tidal effects are becoming more dominant.

Vertical diffusivity is computed as a time-dependent Eulerian field from the turbulence closure, as part of every simulation. Individual particles sample it and compute a random vertical walk. The ensemble mean vertical diffusivity is plotted in Figure 20. It exhibits a jump by three orders of magnitude at about day 153.5 This jump is dramatic, and reinforces the interpretation above the ensemble is shoaling into the mixing zone.

The horizontal center of mass for both forecast ensembles appears in Figure 21. One can clearly see the along-bank drift modulated by the cross-isobath tidal motions. Times of shallow/deep center of mass correspond to times of maximum on/off-bank tidal excursion. A large portion of the vertical motion of the center of mass is cross-isobath tidal advection wherein the ensemble maintains its relative depth. The diffusive case moves shoalward faster, and is slowed down earlier as it engages the mixing front. The fact that its center is still seaward of the front, suggests that only a portion of the ensemble is experiencing mixing. The on-bank motion is enhanced by diffusive exchange with the surface Ekman layer under these winds.

The early time evolution of horizontal ensemble sizes is essentially the same (zero variance) in both cases, up to roughly day 153.5 (Figure 22). Thereafter, the variances undergo dramatic growth in both directions, with the diffusive case becoming roughly a factor of 2-3 larger by the end of the simulation. The highly structured advection in the frontal region is a significant contributor to the total dispersion here; the vertical diffusion amplifies it.

The ensemble variances after day 153.5 are fit to the model of linear-in-time variance growth, to infer an approximate tide-averaged dispersion coefficient. The best fits are shown in the figures in terms of dispersivities. Cross bank, we get $131 \mathrm{~m}^{2} / \mathrm{s}$ total dipsersion, roughly the sum of $52 \mathrm{~m}^{2} / \mathrm{s}$ 


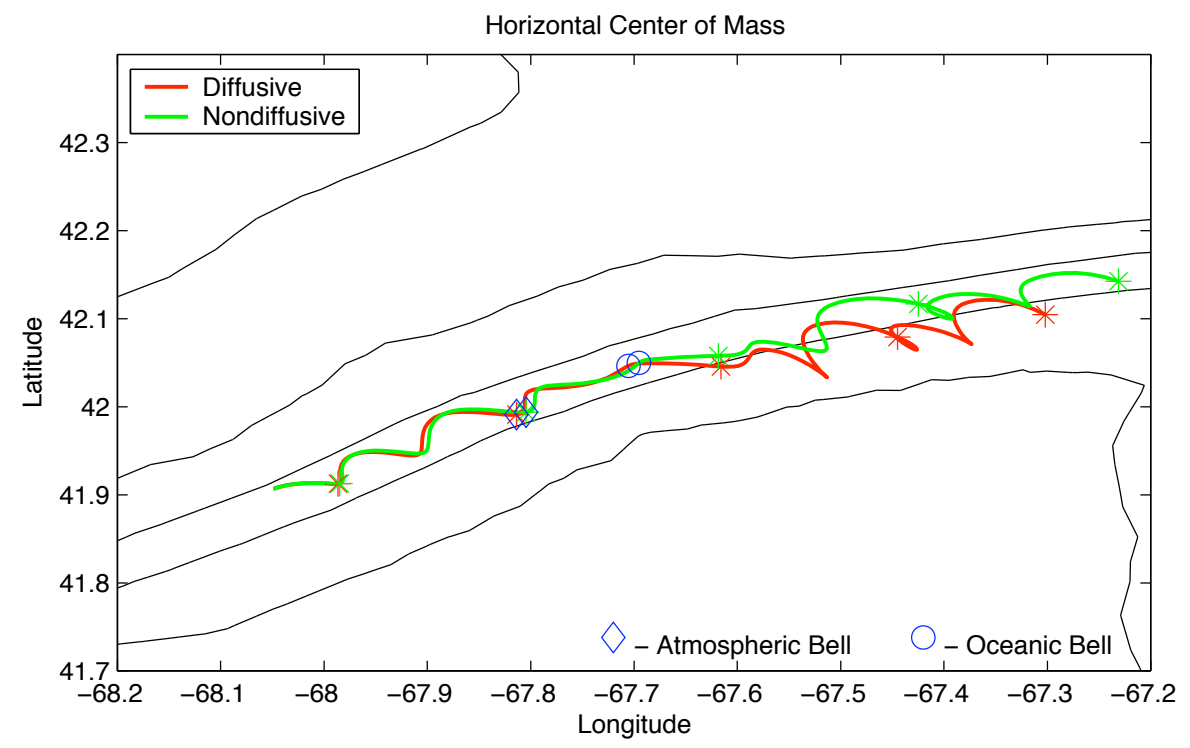

Figure 21: Ensemble mean forecast trajectories, superimposed on the standard topographic contours (black). Asterisks are at daily intervals beginning at $t=152.0$; the two bells are marked. The Simpson-Hunter mixing line is approximately the $50 \mathrm{~m}$ isobath. (Figure 3.)

due to pure advection and an apparent supplement of $79 \mathrm{~m}^{2} / \mathrm{s}$ when vertical diffusion is added. The comparable numbers along-bank are $114 \mathrm{~m}^{2} / \mathrm{s}$ (total), $42 \mathrm{~m}^{2} / \mathrm{s}$ due to advection and $72 \mathrm{~m}^{2} / \mathrm{s}$ added by diffusion.

Other independent estimates for horizontal dispersion in this front are consistent with this. Houghton [12] measured cross-frontal dye dispersion in the bottom boundary layer of the Bank, and obtained the estimates $18-30 \mathrm{~m}^{2} / \mathrm{s}$ cross-bank, and $28-116 \mathrm{~m}^{2} / \mathrm{s}$ along bank. (The lower numbers are for the South Flank; the higher, for Northeast Peak.) These represent total dispersion. We find comparable (order of magnitude) rates for ensembles released in the North Flank pycnocline, once that mechanism is activated by contact with the mixing front.$^{3}$ Otherwise, the offbank horizontal dispersive effect here appears negligible.

Snapshots of the diffusive ensemble distribution reveal a bimodal distribution after the encounter with the front (Figure 23). Overall, the horizontal position of the off-bank part is very similar to that for a nondiffusive ensemble (not shown). Vertical diffusion leads to enhanced horizontal dispersion as the ensemble encounters the front. Diffusive exchange with the surface Ekman layer enhances the on-bank motion and spreading. This spreading extends the ensemble over shallower, differentially moving fluid toward the top of the bank which further acts to draw it out in the alongbank direction.

Time series of the cross-bank distribution (Figure 23, bottom series) show that the diffusive ensemble stays near the surface and compact, as placed, until day 153.5. The onset of the forecast wind event creates vertical mixing, effectively entraining part of the ensemble in the shoalward Ekman drift into the mixing front. A bimodal vertical and horizontal structure develops. The shoalward mode becomes mixed over the entire water column and the mode over deeper water is

\footnotetext{
${ }^{3}$ Here we need to allow for the smaller advective speeds in the bottom boundary layer.
} 

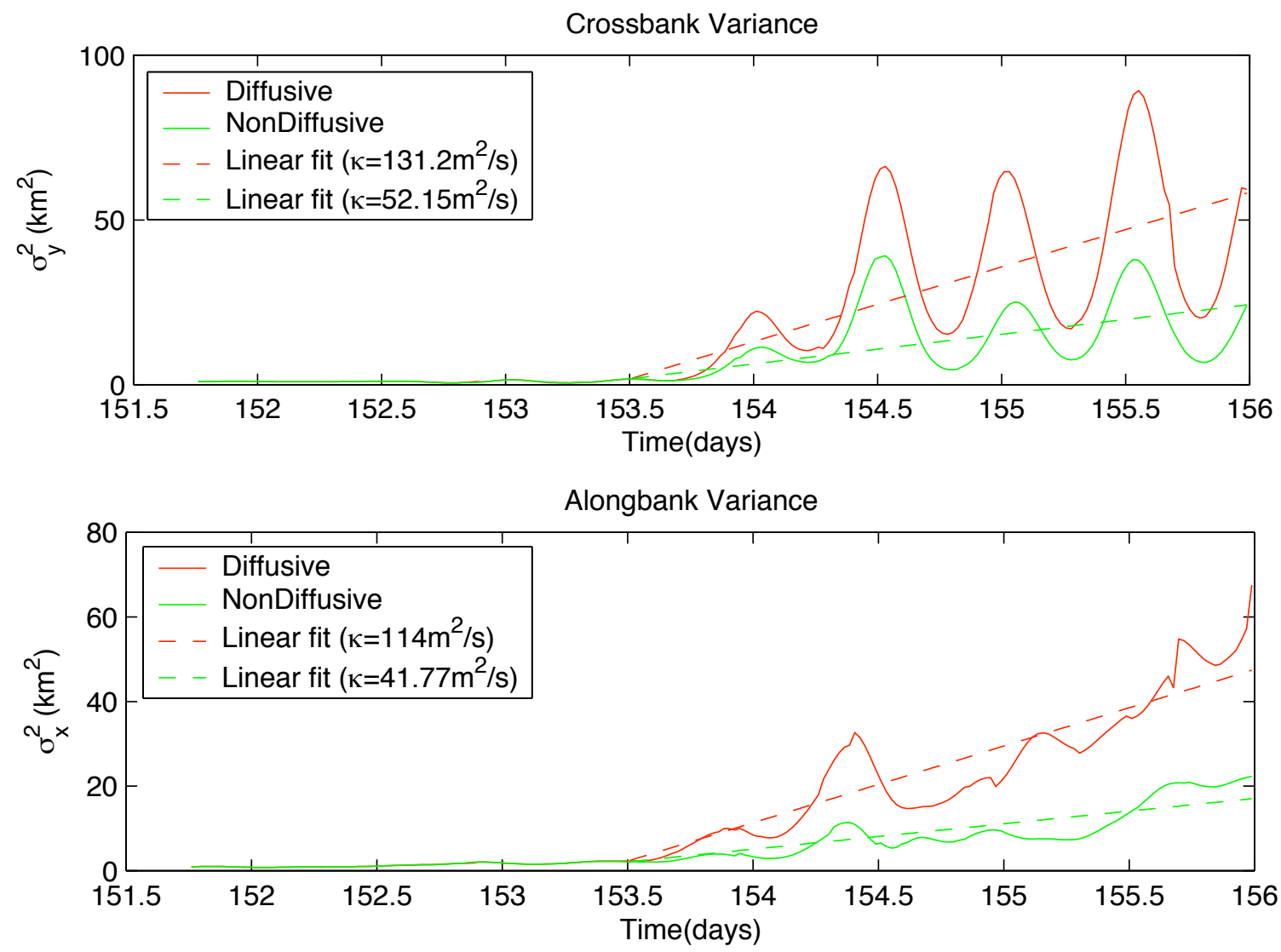

Figure 22: Crossbank and alongbank variance of the forecast ensembles. Here we define along- and cross-bank directions by using the local topography at the time-variable center of mass of the distribution. (This part of the Bank presents fairly homogeneous model topography.)

confined to the upper layer, relatively undisturbed. ${ }^{4}$

The enhanced surface mixed layer created by the wind event, the entrainment of the surface part of the ensemble in shoalward Ekman drift, and the explosive vertical spreading as this sub-ensemble encounters the front are essential features of this forecast. They confirm both simpler analyses of these phenomena, and the realism of the level 2.5 closure with realistic topography and forcing. The resolution of fine-scale simulation features facilitated by the Lagrangian ensemble approach is evident.

\footnotetext{
${ }^{4}$ To obtain a useful cross-bank view in Figure 23, the along-bank variable is "integrated" or aggregated parametrically, using bathymetry below each particle as a surrogate for its cross-bank position. The local topography is relatively monotonic, so the bottom series in Figure 23 is a practical view of the ensemble's effective cross-section.
} 

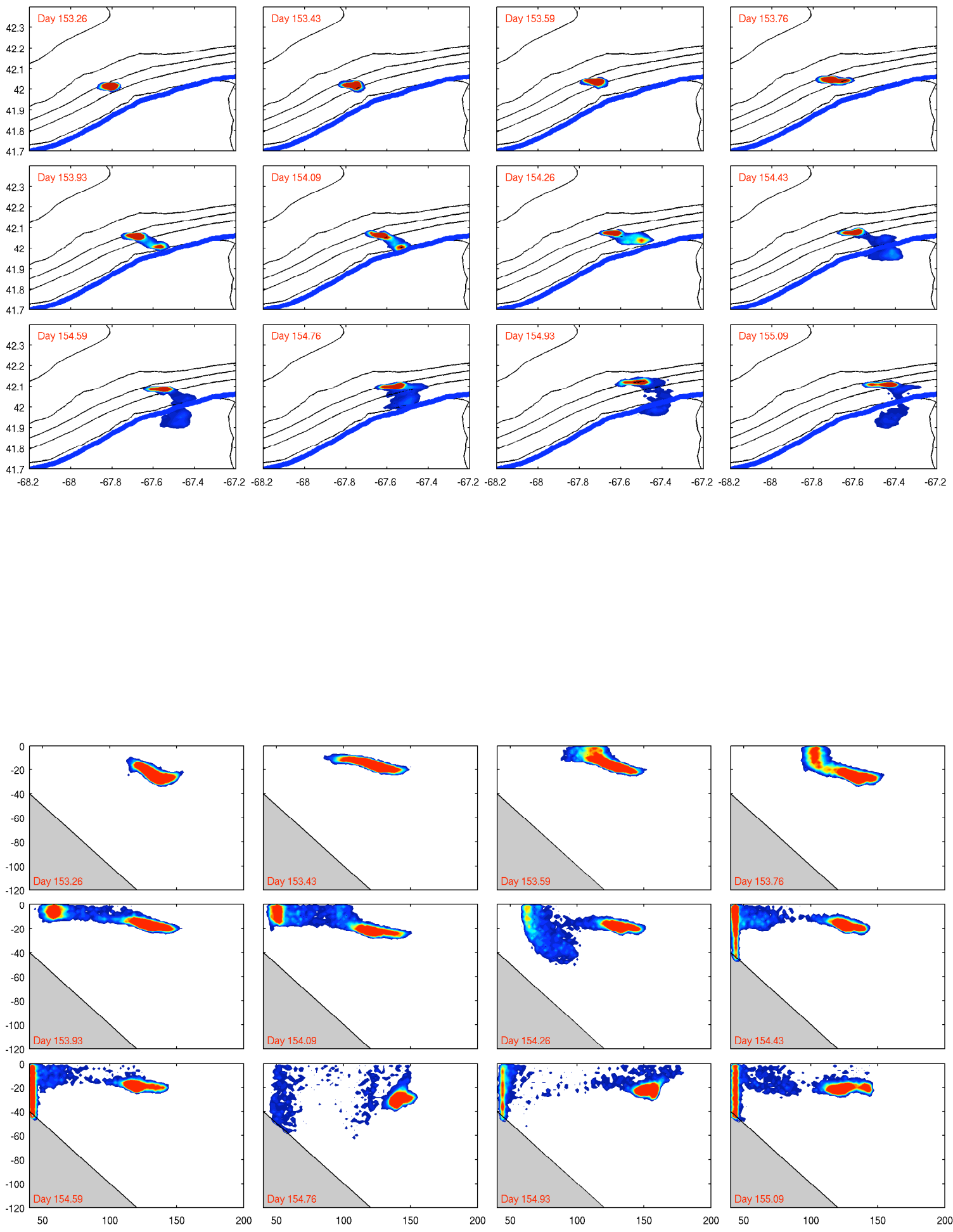

26

Figure 23: Vertically (top series) and horizontally (bottom series) integrated ensemble distribution for the diffusive forecast at selected times. Superimposed on the topography is the time-averaged Simpson-Hunter mixing front (thick blue line). 


\section{Hindcast with Buoy Wind}

Retrospective examination of this period confirms what was observed at sea: that the forecast winds were sometimes not very precise compared with observed values. We see this discrepancy between the forecast wind stress and that recorded at the Georges Bank buoy (Figure 24). Our hypothesis is that the skill shown above is degraded by Ekman drift on-bank which is not supported by the buoy wind.

Accordingly, we made a simulation with nothing changed except the substitution of the retrospective buoy wind for the whole simulation. We refer to this as the "Hindcast" case, since the wind series used is only known retrospectively. We maintain, however, the same sense of the oceanic bell relative to which ADCP data were assimilated.

The simulation results are displayed below. "Hindcast" refers to the use of the Buoy wind; "Forecast" refers to the use of the operational wind forecast available at-sea, as presented in the previous section. There are no other differences among the two simulations.
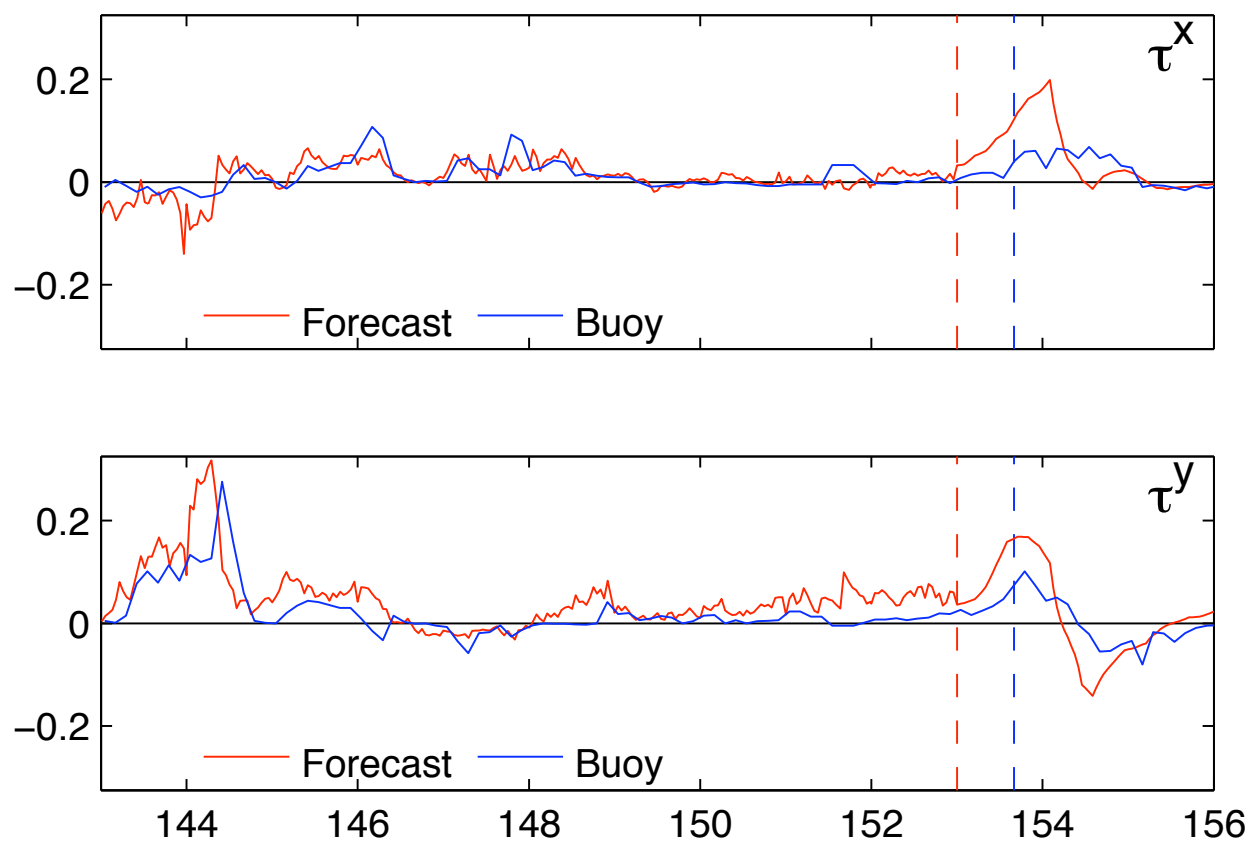

Figure 24: Wind Products $[P a]$. The Forecast wind product is a composite of the NCEP product and the shipboard observation. The Buoy product is used here for the hindcast. It was observed at the Georges Bank Buoy \# 44011 on the South Flank of the Bank. The atmospheric and oceanic bell times are shown for reference.

Only modest hindcast improvement is shown in the ADCP fits, Table 5. This level of improvement is not significant. The ecologically critical cross-bank motion is masked in the larger tidal and along-bank motions. And, the $\mathbf{V}(z)$ misfit is high in both cases.

While the ADCP misfits are not sensitive to this change, the drifter comparisons are. Figure 25 shows simulated and observed drifter results and replots the forecast results for comparison. For 
both drifters, despite differences in launch positions/times, we have the forecast moving on-bank while the hindcast does not. This is more exaggerated than for the centers of mass as in Figure 26, presumably reflecting the on-bank shoaling toward bottom-generated mixing with the fixed depth constraint. But qualitatively, the effect is the same. Also shown are timeseries of drifter separation. For 006, the early separations are basically the same, resembling an exponential rise to about $10 \mathrm{~km}$ over the first day. Thereafter, the hindcast remains at $10 \mathrm{~km}$ while the forecast develops an additional separation at about $5 \mathrm{~km} /$ day, beginning at about day 153.5. Drifter 037 shows both separations initiating growth at about $15 \mathrm{~km}$ /day at that time. The straight lines on these figures represent linear least-squares fits over the entire period and are reported in Table 6 . The hindcast improves this metric of performance in all cases; more significantly, the onbank drift is largely removed.

The diffusive ensemble centers (Figure 26) are less sensitive to the wind change, but show the same qualitative difference. The hindcast ensemble moves along-isobath, while the forecast one develops a cross-isobath component toward the mixing front beginning at about the atmospheric bell (noted above). Recall that the forecast ensemble is bimodal with a portion engaged in the front and a portion off-bank. The hindcast ensemble remains compact through the simulation (see below).
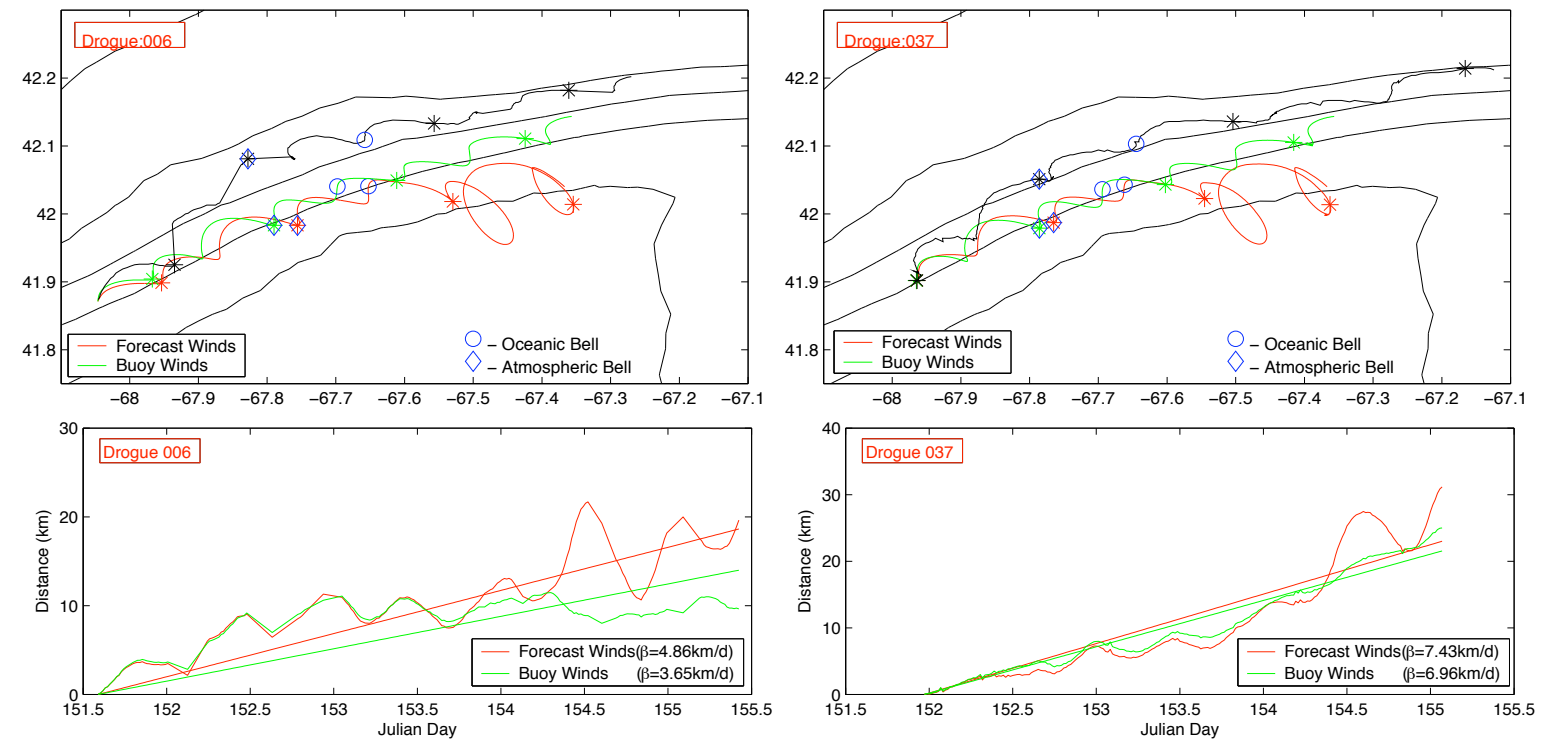

Figure 25: Top Panels - Comparison of observed and simulated fixed-depth drifter tracks for the Hindcast and Forecast cases. The same strong cross-bank gradient in tidal ellipse is present in both cases, with only the Forecast case sampling the on-bank portion. Bottom Panels - Separation between simulated and observed drifters versus time; and the zerointercept, least squares linear fit. Vertical diffusion is active in all cases.

Figure 27 illustrates the ensemble center of mass comparisons with the tracer data. Both hindcast ensembles track along-bank correctly but lag behind the tracer. The diffusive and nondiffusive hindcasts hardly differ; and the separation rate, $3.3 \mathrm{~km} /$ day is unchanged from the forecast (Table 6). Late in the simulation, the forecast and hindcast develop bigger differences (Figure 26). But the data in this comparison end at $\sim$ day 154.8, before that discrepancy develops fully. Also, there 
are important differences in variance growth relative to the forecast (below); but these do not really affect the early center of mass trajectories compared here.

The ensemble variance growth over time is plotted in Figure 28. There is essentially no alongbank dispersion until day 154.5; after that, the vertical diffusion has no effect; the ensemble remains de facto purely advective; its variance is growing due to advective shear dispersion. The same is true for the smaller crossbank dispersion, except that the onset of dispersion is delayed by about a halfday. During the last day, the alongbank variance grows at the high rate $60 \mathrm{~km}^{2} / d\left(\kappa \simeq 350 \mathrm{~m}^{2} / \mathrm{s}\right)$ due to advection. (Caution is advised here as the underlying topography (northeast peak) is not 2-D here, so the cross- and along-isobath directions are poorly defined.)

The vertical diffusivity experienced by this ensemble is very weak, $10^{-5} \mathrm{~m}^{2} / \mathrm{s}$, until day 154.5 , when growth to roughly $10^{-4} \mathrm{~m}^{2} / \mathrm{s}$ occurs (Figure 29 ). This latter value is comparable to that observed on the Northeast Peak by Horne et al. [11]; but it is still 2 orders of magnitude below that experienced by the forecast ensemble. The small additional vertical variance which actually develops in the diffusive hindcast ensemble, illustrated in the lower panel of Figure 28, corroborates this low ensemble diffusivity. (In examining these results, recall that closure-generated diffusivity generates vertical random walk for individuals within the ensemble; variance and variance growth are Lagrangian outcomes of the whole ensemble.)

Tables 5, 6 and 7 summarize the results. Evolution of the hindcast ensemble confirms its low dispersion and general trajectory along-isobath (Figure 30). 


\begin{tabular}{c|cc|cc|}
\cline { 2 - 5 } & \multicolumn{3}{|c|}{ RMS ADCP Misfit $(\mathrm{cm} / \mathrm{s})$} \\
$\overline{\mathbf{V}}$ & \multicolumn{2}{c|}{ V $(z)$} \\
\hline Case Name & Pre-Bell & Post-Bell & Pre-Bell & Post-Bell \\
\hline Forecast Winds & 4.77 & 8.72 & 10.07 & 16.36 \\
Hindcast (Buoy) Winds & 4.69 & 8.72 & 9.81 & 16.16 \\
\hline
\end{tabular}

Table 5: RMS ADCP misfit metrics as in Table 3 for two cases. The model fit metrics for the forecast are identical to those recorded in Table 3. The hindcast lacks the wind event which is forecast in the former. As in Table 3, the data are divided into active (pre-oceanic bell) and passive (post-bell) and the same ADCP data are assimilated as before, on the same schedule.

\begin{tabular}{c|ccc|}
\cline { 2 - 4 } & \multicolumn{3}{|c|}{ Estimates of Separation Rate $(\mathrm{km} / \mathrm{d})$} \\
& Drifter 006 & Drifter 037 & Dye \\
\hline Forecast Winds & 4.86 & 7.43 & 3.32 \\
Hindcast (Buoy) Winds & 3.65 & 6.96 & 3.33 \\
\hline
\end{tabular}

Table 6: Summary of estimates for drifter and dye separation rates. The drifters are compared with fixed-depth advection only. The forecast data are the same as in Table 4. The dye case refers to the center of mass estimate relative to the diffusive ensemble mean position. The least squares fit assumes linear separation in time, and zero initial separation.

\begin{tabular}{c|ccc|ccc|}
\cline { 2 - 6 } & \multicolumn{4}{|c|}{ Estimates of Horizontal Dispersion Rate $\left(m^{2} / s\right)$} \\
Cross-Bank & \multicolumn{3}{c|}{ Along-Bank } \\
Case Name & Total & Advection & + Diffusion & Total & Advection & + Diffusion \\
\hline Forecast Winds & 131. & 52. & 79. & 114. & 42. & 72. \\
Hindcast (Buoy) Winds & 21. & 19. & 2. & 74. & 72. & 2. \\
\hline
\end{tabular}

Table 7: Summary of model estimates for effective horizontal dispersion, once an ensemble from the pycnocline encounters the frontal zone. "Dispersion" is horizontal spreading. "Advection" is 3-D tidal-time advective transport only. "Diffusion" is the added effect of vertical diffusion. "Total" is the combined dispersion rate. 

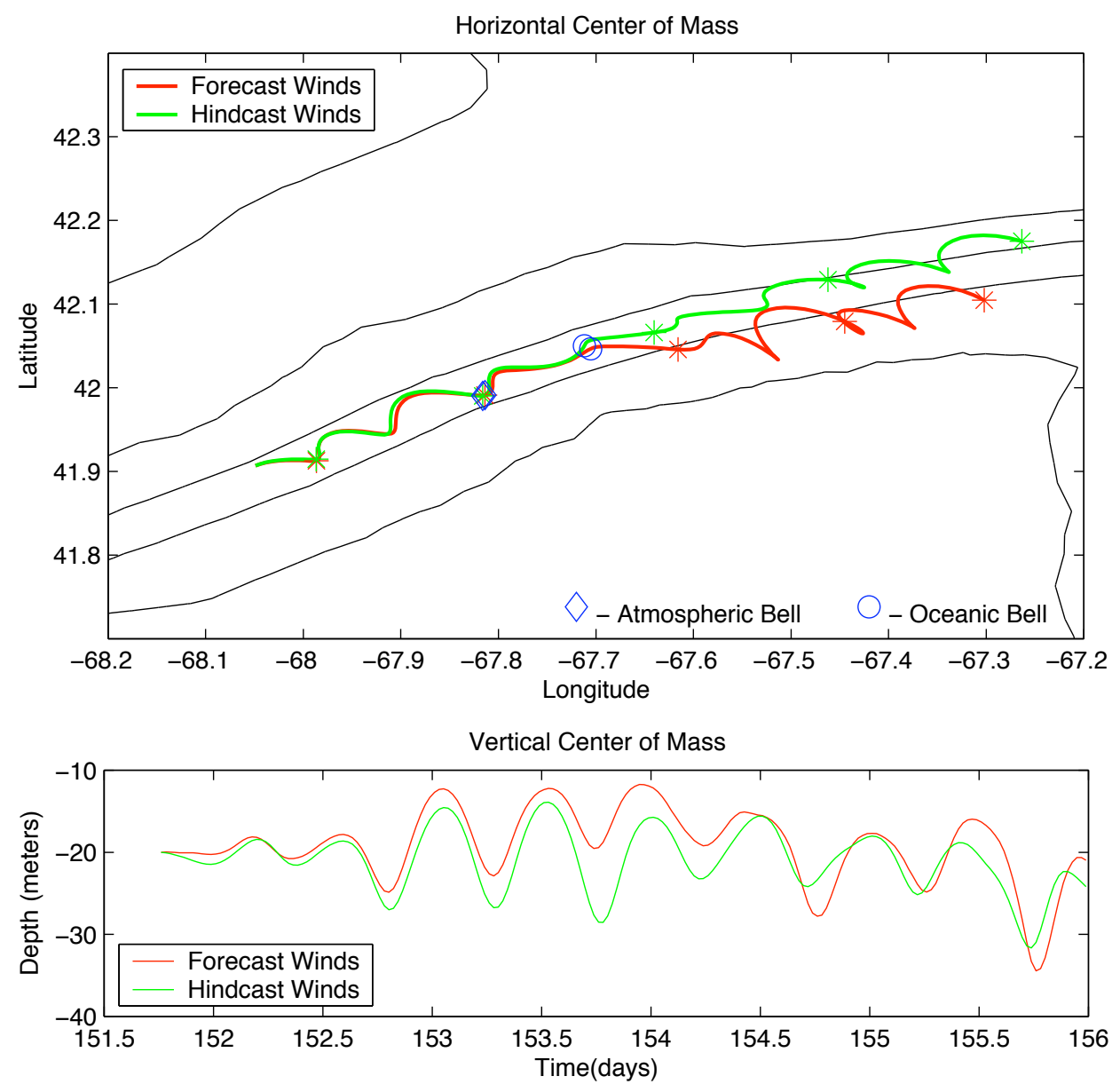

Figure 26: Ensemble mean position for diffusive Forecast and Hindcast ensembles. The Forecast case is unchanged from that presented in Figure 21. Asterisks are separated by one day; the bell times are also shown. Vertical diffusion is active in both cases. 

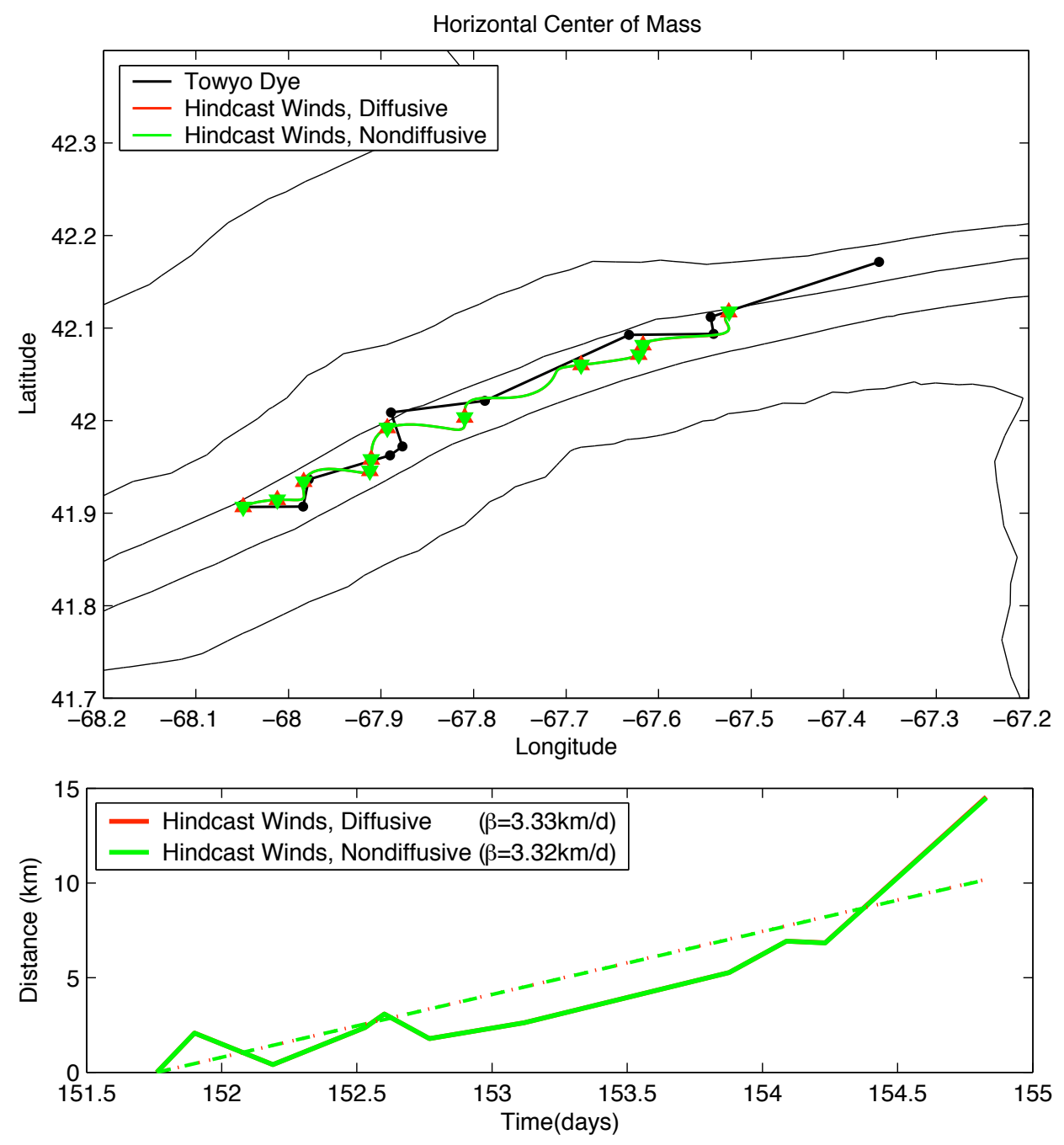

Figure 27: Hindcast with Buoy Wind. Observed and ensemble centers of mass (top) and separation rates (bottom). These data end at $\sim$ day 154.8 . 

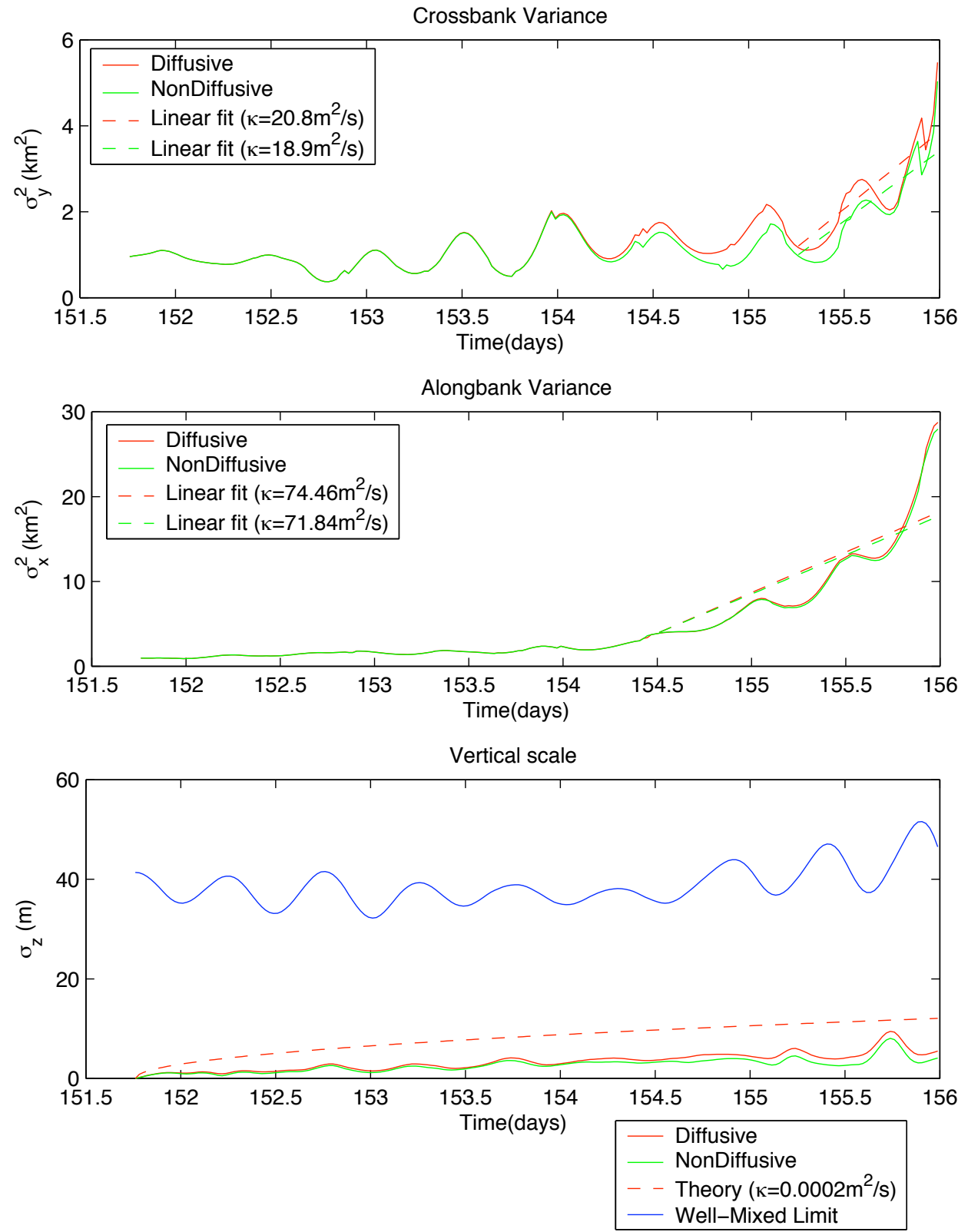

Figure 28: Hindcast with Buoy Wind. Ensemble variance versus time. 


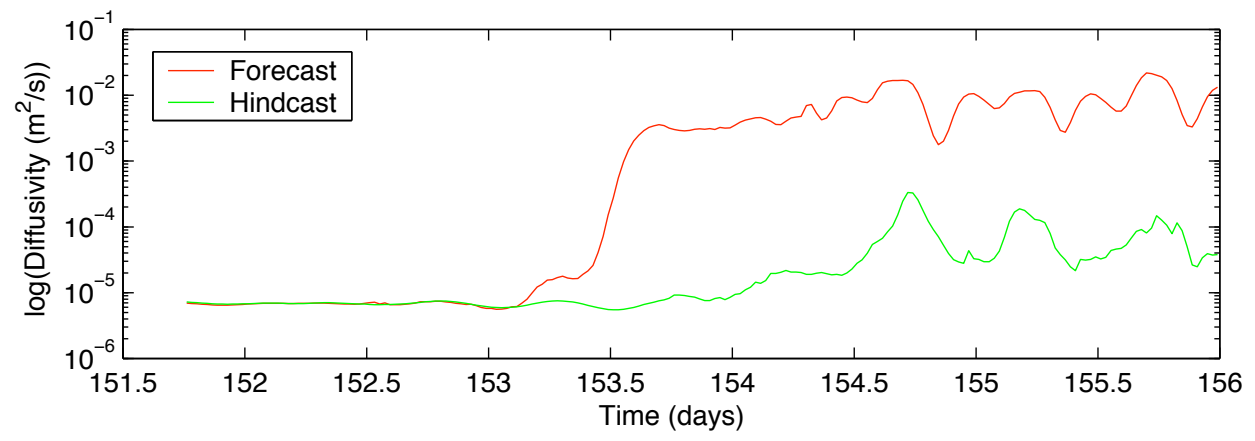

Figure 29: Ensemble-mean vertical diffusivity versus time, as computed by level 2.5 closure in the diffusive hindcast and forecast simulations. 

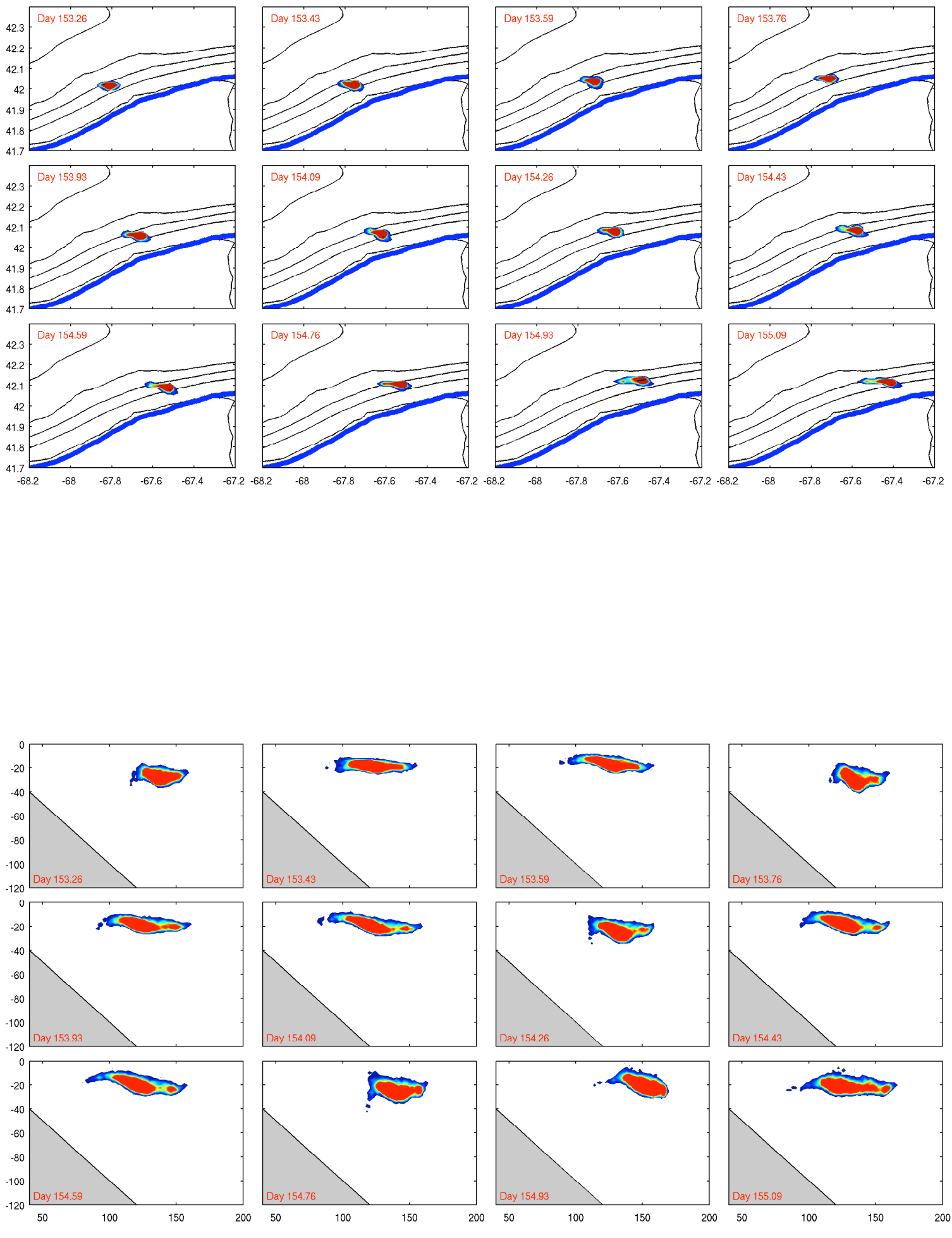

35

Figure 30: Diffusive hindcast ensemble distribution versus time. As in Figure 23. 


\section{Conclusions}

Our results are credible representatives of "the possible" but not perfect reproductions of the past. They are like historical fiction - realistic processes which are consistent with the facts. The hindcast is closer to historical truth, based on first principles - better information forcing the same processes.

Lagrangian dispersion is event-specific; and the two events created here are dramatically different. Off-bank, both ensembles are essentially non-diffusive. As an ensemble engages the mixing front, the diffusivity rises by 3 orders of magnitude and initiates horizontal spreading in the complex front. The resultant dispersion rate is estimated at (114., 131.) $\mathrm{m}^{2} / \mathrm{s}$ (along-bank, cross-bank), partitioned roughly as $1 / 3$ pure $3-\mathrm{D}$ advection and $2 / 3$ initiated by vertical diffusion. This occurred in the forecast ensemble as a result of Ekman drift and turbulence generated by both wind and tide. In the hindcast ensemble, quiescent wind left the ensemble nondiffusive and compact, advecting parallel to the mixing front and experiencing some advective shear dispersion.

Relative to Data-Assimilative Skill:

1) Hydrographic skill is good; simulations driven by standard heat flux estimates retain this skill over timescales of weeks. No special detiding or other adjustment for synopticity appears necessary.

2) Velocity skill as judged by vertically-averaged ADCP data is similar to that achieved in similar studies. The hindcast correction to the wind input did not significantly improve the ADCP fit. The vertically-dependent velocity misfit shows higher variance in both cases.

3) Lagrangian drifter and tracer center-of-mass skill are consistent with each other, and with previous drifter studies. The near-surface bias under erroneous wind is apparent here as an on-bank bias in Lagrangian trajectories.

4) Small misfits in cross-front velocity and integrated Lagrangian trajectories result in big differences in transport. Encountering the mixing front represents a major event relative to ensemble variance growth; there are nonlinear but smaller effects on center of mass as well.

5) Wind forcing is critical and wind products based on published meteorological models at coarser resolution are sometimes deficient for these purposes. The hindcast shows this both in the wind signal itself and in the circulation results. Better fidelity of hindcast and forecast is needed in the local atmospheric forecast.

6) Assimilation of vertically-averaged velocity masks some depth-dependent vertical biases. In this case, the Ekman drift in the mixed layer can be missed. This bias shows up in Lagrangian separations from forecast trajectories. Procedures for assimilation of $\mathrm{V}(\mathrm{z})$, and of Lagrangian displacement, would help this.

Relative to Dispersion:

7) With advanced tidal and topographic resolution there is no role for explicit tidal-time horizontal dispersion; it is an emergent property of ensemble spreading with 3-D advection and vertical diffusion controlled by wind, tide, and stratification.

8) Horizontal dispersion in this system depends on a) 3-D tidal time advection and b) 1-D vertical diffusion. These fields are very strongly structured in space-time. Bottom-generated turbulence, and baroclinic tidal rectification, fixes the general location and structure of the front on the topography. Wind events can enhance its dispersive effect, by a) earlier encounter with the front; b) 
enhanced vertical exchange with the near-surface; and c) enhanced surface shear in the advective field.

9) Use of Lagrangian ensemble methods for this purpose is effective and recommended for future study. In particular, particles can operate in limiting non-diffusive regimes without the usual Peclet number restrictions associated with Eulerian simulations. And, as their positions are never lost or blurred, they are effective in high-gradient situations as shown here.

10) Characterization of ensemble evolution is straightforward, in terms of moments of the particle distribution. Evolution of ensemble size is an inevitable need when dilution leads to undersampling. This is readily automated by processes analogous to spawning events simulated for living particles.

Outstanding problems remain, pertaining to Lagrangian ensemble methods. All require adherence to an underlying statistical theory of Lagrangian displacement in a turbulent fluid, sufficient to inform

1) field sampling

2) simulation

3) construction of skill metrics

4) skill interpretation

5) data assimilation

Related is the need for a better Lagrangian model of drifter motion.

The level 2.5 turbulence closure used herein appears adequate to describe the interactions with the mixing front and the attendant ensemble variance growth. Off-bank, however, near-surface mixing involves processes not clearly described in the present calculations, operative in and above the pycnocline in deep water. The basal diffusivity used here appears adequate for heat and salt transport there; it seems to be making up for coarse resolution and parameterization of processes in the air-sea exchange zone. Deeper into the water column, available evidence suggests a much more quiescent environment (by at least an order of magnitude). The transport pathway to the Bank from the north is via this environment and ensemble variance growth is sensitive to the mixing there. In particular, the probability of an ensemble located in the pycnocline, becoming involved with an overlying Ekman layer and its horizontal transport, is at stake here. Available evidence supports the "no diffusion" limit used here, with level 2.5 diffusion once the mixing front has been encountered. More research is needed into the operative mixing processes in this environment both at the surface and below it.

\section{Acknowledgements}

We are grateful for the help of participants aboard ENDEAVOR 324 who assisted in aspects of data interpretation, at sea and afterward. James Manning assisted us with the initial conditions on temperature and salinity; Cabell Davis and the WHOI VPR group provided the towyo'd CTD data; James Churchill provided the drifter data; Charles Flagg helped with the real-time ADCP networking; Valery Kosnyrev asisted with the data collection and execution of the at-sea forecasts. Keston Smith and Ata Bilgili provided valuable advice and critique during the modeling. This work was sponsored by USGLOBEC, a joint program of the US National Science Foundation and the National Oceanic and Atmospheric Administration. This is USGLOBEC Contribution \# 435; and Contribution \# 11239 of the Woods Hole Oceanographic Institution. 


\section{References}

[1] A. Aretxabaleta, J. Manning, F.E. Werner, K. Smith, B.O. Blanton, and D.R. Lynch. Hindcasting May 1999 on the Southern Flank of Georges Bank: frontal circualtion and implications. Cont. Shelf Res., in press, 2004.

[2] R.H. Backus and D.W. Bourne, editors. Georges Bank. MIT, 1987.

[3] R. Beardsley, P. Smith, C. Lee, C. Chen, J. Churchill, S. Lentz, and S. Werner, editors. Physical Processes on Georges Bank, volume 108 of Special Section. J. Geophys. Res., 2003.

[4] P. Berrien and J. Sibunka. Distribution Patterns of Fish Eggs in the U.S. Northeast Continental Shelf Ecosystem, 1977-1987. , NOAA Technical Report NMFS 145, U.S. Dept. of Commerce, 1999.

[5] A. F. Blumberg, B. Galperin, and D. J. O'Connor. Modeling vertical structure of open-channel flows. ASCE J. Hydraulic Engg., 118:1119-1134, 1992.

[6] G.T. Csanady. Turbulent Diffusion in the Environment, volume 3 of Geophysicss and Astrophysics Monographs. D. Reidel, 1976.

[7] K.N. Dimou and E.E. Adams. A random-walk, particle tracking model for well-mixed estuaries and coastal waters. Est. Coast. Mar. Sci., 37:99-110, 1993.

[8] H.B. Fischer, E.J. List, R.C.Y. Koh, J. Imberger, and N.H. Brooks. Mixing in Inland and Coastal Waters. Academic Press, 1979.

[9] B. Galperin, L.H. Kantha, S. Hassid, and A. Rosati. A quasi-equilibrium turbulent energy model for geophysical flows. J. Atmos. Sci., 45:55-62, 1988.

[10] W.R. Geyer. Field calibration of mixed layer drifters. J. Atmos. Ocean. Tech., 6:333-342, 1989.

[11] E.P.W. Horne, J.W. Loder, C.E. Naimie, and N.S. Oakey. Turbulence dissipation rates and nitrate supply in the upper water column on Goerges Bank. Deep Sea Res. II, 43(7-8):1683$1712,1996$.

[12] R.W. Houghton. Diapycnal flow through a tidal front: a dye tracer study on Georges Bank. J. Mar. Systems, 37(1-3):31-46, 2002.

[13] J.R. Hunter, P.D. Craig, and H.E. Phillips. On the use of random walk models with spatially variable diffusivity. $J C P, 106: 366-376,1993$.

[14] J.A. Ledwell, T.F. Duda, M.A. Sundermeyer, and H.E. Seim. Mixing in a Coastal Environment Part I: A View from Dye Dispersion. J. Geophys. Res., in press, 2004.

[15] J.W. Loder, C.K. Ross, and P.C. Smith. A space- and time-scale characterization of circulation and mixing over submarine banks, with application to the Northwest Atlantic Continental Shelf. Can. J. Fish. Aquat. Sci., 45:1860-1885, 1988.

[16] D. R. Lynch, J. T. C. Ip, C. E. Naimie, and F. E. Werner. Convergence studies of tidallyrectified circulation on Georges Bank. In D. R. Lynch and A. M. Davies, editors, Quantitative Skill Assessment for Coastal Ocean Models, pages 153-174. Coastal and Estuarine Series 48, American Geophysical Union, Washington,DC, 1995. 
[17] D.R. Lynch. Coupled physical/biological models of the coastal ocean. Naval Research Reviews, 51(2):2-15, 1999.

[18] D.R. Lynch, W.C. Gentleman, D.J. McGillicuddy, and C. Davis. Biological/physical simulations of Calanus finmarchicus population dynamics in the Gulf of Maine. Mar. Ecol. Prog. Ser., 169:189-210, 1998.

[19] D.R. Lynch and Charles G. Hannah. Inverse Model for Limited-Area Hindcasts on the Continental Shelf. J. Atmospheric and Oceanic Technology, 18:962-981, 2001.

[20] D.R. Lynch, J.T.C. Ip, F.E. Werner, and E.M. Wolff. Environmental Hydrodynamics: Comprehensive Model of the Gulf of Maine. In G.F. Carey, editor, Finite Element Modeling of Environmental Problems, chapter 2, pages 17-38. John Wiley, 1995.

[21] D.R. Lynch and D.J. McGillicuddy. Objective Analysis for Coastal Regimes. Contin. Shelf Res., 21:1299-1315, 2001.

[22] D.R. Lynch, C. Naimie, J. Ip, C. Lewis, F. Werner, B. Blanton R. Luettich, J. Quinlan, D. McGillicuddy, J. Ledwell, J. Churchill, V. Kosnyrev, C. Davis, S. Gallager, C. Ashjian, G. Lough, J. Manning, C. Flagg, C. Hannah, and R. Groman. Real-Time Data Assimilative Modeling on Georges Bank. Oceanography, 14:65-77, 2001.

[23] D.R. Lynch and C.E. Naimie. Hindcasting the Georges Bank circulation, part II: wind-band inversion. Contin. Shelf Res., 22:2191-2224, 2002.

[24] D.R. Lynch, C.E. Naimie, and C.G. Hannah. Hindcasting the Georges Bank Circulation: Part I, Detiding. Contin. Shelf Res., 18:607-639, 1998.

[25] A.J. Mariano, A. Griffa, T.M. Ozgokmen, and E. Zambianchi. Lagrangain Analysis and Predictability of Coastal and Ocean Dynamics 2000. J. Atmos. Ocean. Tech., 19(7):1114-1126, 2002.

[26] D.J. McGillicuddy Jr., D.R. Lynch., A.M. Moore, W.C. Gentleman, C.S. Davis, and C.J. Meise. An adjoint data assimilation approach to diagnosis of physical and biological controls on Pseudocalanu spp. in the Gulf of Maine-Georges Bank region. Fish. Oceanogr., 7(3/4):205218, 1998.

[27] C. J. Meise and J. E. O'Reilly. Spatial and seasonal patterns in abundance and age-composition of Calanus finmarchicus in the Gulf of Maine and on Georges Bank. Deep Sea Res. II, 43(78):1977-1987, 1996.

[28] G. L. Mellor and T. Yamada. A hierarchy turbulence closure models for planetray boundary layers. $J A S, 31: 1791-1806,1974$.

[29] G. L. Mellor and T. Yamada. Development of a turbulence closure model for geophysical fluid problems. Reviews of Geophys. Space Phys., 20:851-875, 1982.

[30] C.B. Miller, D.R. Lynch, F. Carlotti, W. Gentleman, and C. Lewis. Coupling of an individualbased population dynamics model for stocks of Calanus finmarchicus with a circulation model for the Georges Bank region. Fish. Oceanogr., 7(3-4):219-234, 1998.

[31] C. Naimie, R. Limeburner, C. Hannah, and R. Beardsley. On the geographic and seasonal patterns of the near-surface circulation on Georges Bank - from real and simulated drifters. Deep Sea Res. II, 48:501-518, 2001. 
[32] C.E. Naimie. Georges Bank residual circulation during weak and strong stratification periods - Prognostic numerical model results. J. Geophys. Res., 101(C3):6469-6486, 1996.

[33] P.P. Niiler, A.S. Sybrandy, K. Bi, P.M. Poulan, and D. Bitterman. Measurements of the waterfollowing capability of holey-sock and TRISTAR drifters. Deep Sea Res., 42(11-12):1951-1964, 1995.

[34] A. Okubo. Dynamical aspects of animal grouping: Swarms, schools, flocks, and herds. In M. Kotani, editor, Advances in Biophysics, volume 22, pages 1-94. Japan Scientific Societies Press, 1986.

[35] J.E. O'Reilly and C. Zetlin. Seasonal, Horizontal, and Vertical Distribution of Phytoplankton Chlorophyll $a$ in the Northeast U.S. Continental Shelf Ecosystem. , NOAA Technical Report NMFS 139, U.S. Dept. of Commerce, 1998.

[36] J.A. Proehl and D.R Lynch. Experiments in Lagrangian Diffusion. Numerical Methods Laboratory Report, NML 01-5, 2001.

[37] H. Ridderinkhof. Lagrangian flows in complex eulerian current fields. In D. R. Lynch and A. M. Davies, editors, Quantitative Skill Assessment for Coastal Ocean Models, pages 31-48. Coastal and Estuarine Series 47, American Geophysical Union, Washington,DC, 1995.

[38] K. Sherman, M. Grosslein, D. Mountain, D. Busch, J. O'Reilly, and R. Theroux. The Northeast Shelf Ecosystem: An Initial Perspective. In The Northeast Shelf Ecosystem. Assessment, Sustainability, and Management, pages 103-126. Blackwell, 1996.

[39] J.H. Simpson and J.R. Hunter. Fronts in the Irish Sea. Nature, 250:404-406, 1974.

[40] J.G. Skellam. Random Dispersal in Theoretical Populations. Biometrika, 38:196-218, 1951.

[41] M.J. Tremblay, J.W. Loder, F.E. Werner, C.E. Naimie, F.H. Page, and M.M. Sinclair. Drift of Sea Scallop larvae Placopecten magellanicus on Georges Bank: a model study of the roles of mean advection, larval behaviour, and larval origin. Deep Sea Res. II, 41(1):7-49, 1994.

[42] D.S. Ullman, A.C. Dale, D. Hebert, and J.A. Barth. The front on the Northern Flank of Georges Bank in spring: 2. Cross-frontal fluxes and mixing. J. Geophys. Res., 108(C11), 2003.

[43] A.W. Visser. Using random walk models to simulate the vertical distribution of particles in a turbulent water column. Mar. Ecol. Prog. Ser., 158:275-281, 1997.

[44] F.E. Werner, R.I. Perry, R.G. Lough, and C.E. Naimie. Trophodynamic and advective influences on Georges Bank larval cod and haddock. Deep Sea Res. II, 43(7-8):1793-1822, 1996.

[45] P.H. Wiebe and R.C. Beardsley, editors. Physical-Biological Interactions on Georges Bank and its Environs, volume 43(7-8) of Topical Studies in Oceanography. Deep-Sea Research II, 1996.

[46] P.H. Wiebe, R.C. Beardsley, A.C. Bucklin, and D.G. Mountain, editors. Coupled Biological and Physical Studies of Plankton Populations: Georges Bank and Related North Atlantic Regions, volume 48(1-3) of Topical Studies in Oceanography. Deep-Sea Research II, 2001. 